Anna Paula Rocha Malheiros

\title{
Resultado do tratamento da doença de Crohn com anti-fator de necrose tumoral alfa
}

Dissertação apresentada à Faculdade de Medicina da Universidade de São Paulo para obtenção do título de Mestre em Ciências

Área de concentração: Cirurgia do Aparelho Digestivo Orientadora: Prof ${ }^{a}$. Dra. Magaly Gemio Teixeira

São Paulo 2008 
Dados Internacionais de Catalogação na Publicação (CIP)

Preparada pela Biblioteca da

Faculdade de Medicina da Universidade de São Paulo

Creprodução autorizada pelo autor

Malheiros, Anna Paula Rocha

Resultado do tratamento da doença de Crohn com anti-fator de necrose tumoral alfa / Anna Paula Rocha Malheiros. -- São Paulo, 2008.

Dissertação(mestrado)--Faculdade de Medicina da Universidade de São Paulo. Departamento de Gastroenterologia.

Área de concentração: Cirurgia do Aparelho Digestivo.

Orientadora: Magaly Gemio Texeira.

Descritores: 1.Doença de Crohn/terapia 2.Fator de necrose tumoral alfa 3.Anticorpos monoclonais/uso terapêutico

USP/FM/SBD-139/08 


\section{DEDICATÓRIA}

Dedico esta dissertação à minha querida e estimada Mestre Professora Doutora

\section{Magaly Gemio Teixeira.}

Obrigada por acreditar mais uma vez em seus alunos e sempre continuar a nos educar: como bons profissionais, indivíduos com ética, respeito e doação.

É sempre uma honra poder estar ao seu lado e tê-la como exemplo, mestre e amiga.

Sinceramente, obrigada. 


\section{AGRADECIMENTOS}

Gostaria de agradecer todas as pessoas que compartilharam comigo de alguma forma a elaboração deste trabalho.

Aos pacientes do ambulatório de Doenças Inflamatórias Intestinais do Hospital das Clínicas da Faculdade de Medicina da Universidade de São Paulo, que sempre atenciosos responderam todos os questionários, aceitaram nosso tratamento e pesquisa, sem eles não haveria a realização deste projeto.

Ao meu marido, Sergio Botelho Incao, por todo amor, compreensão e apoio sempre presente em todos os dias desde que nos conhecemos. É incondicional o seu apoio em todas as minhas conquistas profissionais. Amo você.

A minha mãe, Dra. Elizabeth Ramires Rocha, e minha avó, Catharina Ramires Rocha (in memoriam), por serem tão preciosas em minha vida todos os dias.

Ao meu pai, Hugo Antônio do Amaral Malheiros, por sempre me apoiar e incentivar minha carreira.

Ao meu padrasto, Dr. Carlos Alfredo de Freitas, por ter sido o primeiro exemplo de médico na minha vida.

Aos amigos e colegas do Hospital das Clínicas da Faculdade de Medicina da Universidade de São Paulo.

As secretárias do Departamento de Cirurgia do Aparelho Digestivo, bibliotecárias e funcionários deste Serviço que sempre foram atenciosos e disponíveis para me ajudar.

Aos amigos, Dra. Fernanda Sanfront e Dr. Erodilho Sande Mota, por toda amizade, carinho e apoio todos estes anos de convivência, por serem excelentes proctologistas, professores no meu aprendizado, inclusive para realização desta dissertação.

À Dra. Maristela Gomes de Almeida e Dr. César de Almeida Neto por sempre me acolherem como amigos e compartilharem seus conhecimentos comigo durante a elaboração desta dissertação. Em especial à Dra. Maristela que muito antes deste sonho acontecer já era um exemplo de batalha e sucesso em proctologia para mim.

Ao Professor Dr. Desidério Roberto Kiss que desde a minha residência de cirurgia geral me acolheu nos braços da proctologia e me mostrou a importância de ampliar meus conhecimentos. 
À Professora Doutora Angelita Habr-Gama que é o nosso maior ícone de dedicação à vida acadêmica e científica, sendo sempre um exemplo para todos os seus alunos.

Ao amigo, Dr. Edésio Vieira Silva Filho, colega sempre disponível e carinhoso com todos do ambulatório de doenças inflamatórias intestinais.

Ao Professor Dr. Paulo de Arruda Alves por estar sempre disposto a nos ensinar proctologia, ciências e cultura com todo o seu entusiasmo e alegria que nos é contagiante

Ao meu irmão Dr. Luiz Gustavo, minha cunhada Mariana e sobrinha Luana (à caminho), por serem sempre a minha família amada. 


\section{Normalização adotada}

Esta dissertação está de acordo com as seguintes normas:

Referências: adaptado de International Committee of Medical Journals Editors (Vancouver)

Universidade de São Paulo. Faculdade de Medicina. Serviço de Biblioteca e Documentação. Guia de apresentação de dissertações, teses e monografias. Elaborado por Anneliese Carneiro da Cunha, Maria Julia de A. L. freddi, Maria F. Crestana, Marinalva de Souza Aragão, Suely Campos Cardoso, Valéria Vilhena. $2^{a}$ ed. São Paulo: Serviço de Biblioteca e Documentação; 2005.

Abreviaturas dos títulos dos periódicos de acordo com List of Journals Indexed in Index Medicus. 


\section{SUMÁRIO}

Lista de abreviaturas

Lista de Tabelas

Lista de Gráficos

Resumo

Summary

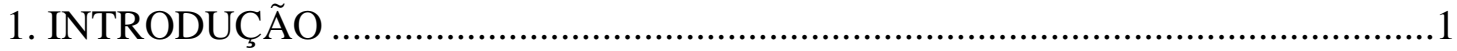

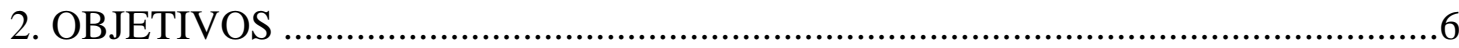

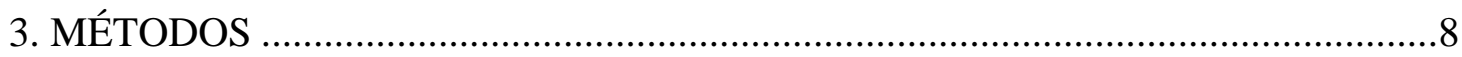

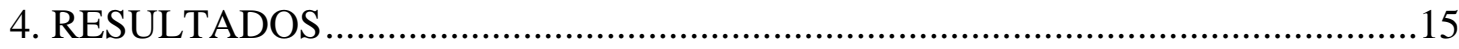

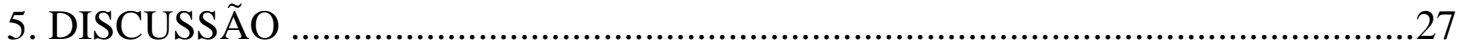

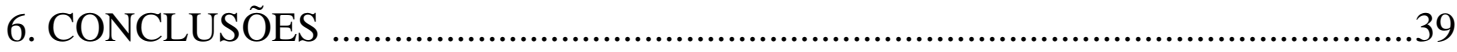

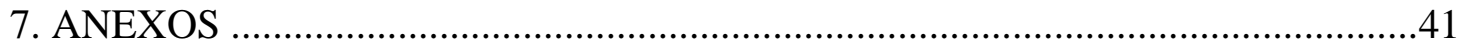

Anexo 1 - Protocolo de pesquisa ........................................................................42

Anexo 2 - IADC - Índice de atividade da doençca de Crohn..................................43

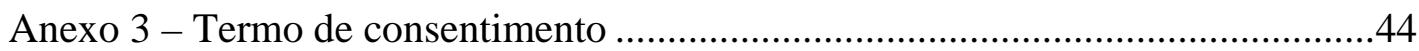

Anexo 4 - Distribuição dos doentes com DC segundo o IADC que foram tratados

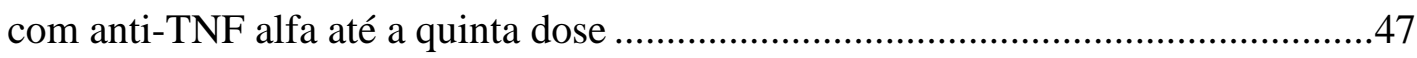

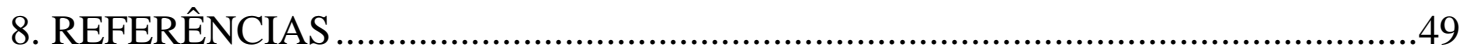




\section{LISTA DE ABREVIATURAS}

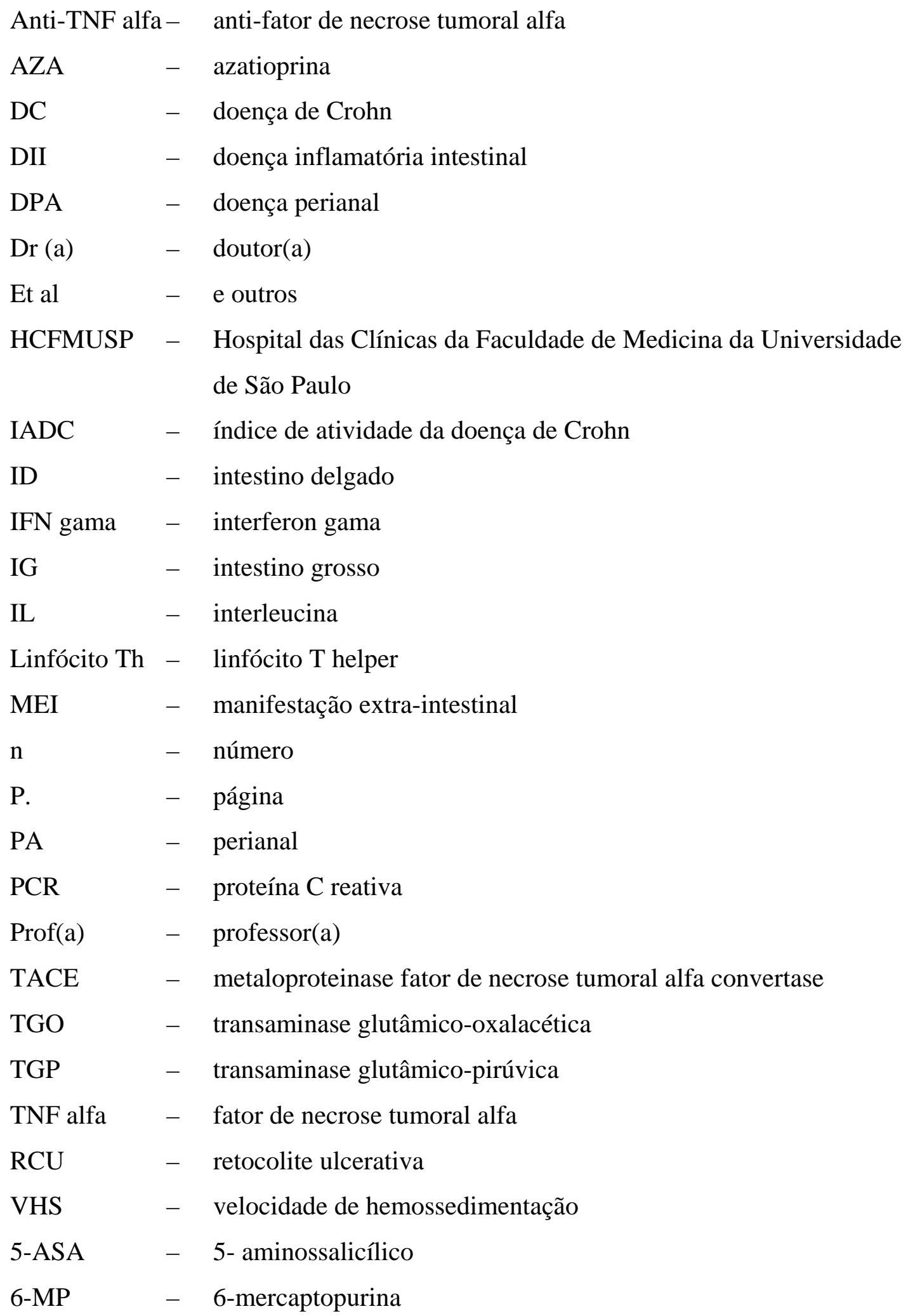




\section{LISTA DE TABELAS}

Tabela 1: Distribuição dos doentes com DC segundo a localização da doença que foram tratados com anti-TNF alfa

Tabela 2: Distribuição dos doentes com DC segundo as medicações associadas que foram tratados com anti-TNF alfa

Tabela 3: Distribuição dos doentes com DC segundo o número de doses aplicadas de anti-TNF alfa

Tabela 4: Distribuição dos doentes com DC segundo os resultados quanto à avaliação do estado geral em relação a cada aplicação que foram tratados com anti-TNF alfa

Tabela 5: Distribuição dos doentes com DC segundo os resultados quanto à avaliação dos sintomas intestinais em relação a cada aplicação que foram tratados com anti-TNF alfa

Tabela 6: Distribuição dos doentes com DC segundo os resultados quanto à avaliação da doença perianal em relação a cada aplicação que foram tratados com anti-TNF alfa 


\section{LISTA DE GRÁFICOS}

Gráfico 1: Distribuição dos doentes com DC segundo a idade e sexo que foram tratados com anti-TNF alfa

Gráfico 2: Distribuição dos doentes com DC segundo o tempo de diagnóstico e o resultado do tratamento em relação ao estado geral dos doentes tratados com antiTNF alfa

Gráfico 3: Distribuição dos doentes com DC segundo o tempo de diagnóstico e o resultado do tratamento em relação aos sintomas intestinais dos doentes tratados com anti-TNF alfa

Gráfico 4: Distribuição dos doentes com DC segundo o tempo de diagnóstico e o resultado do tratamento em relação à doença perianal dos doentes tratados com anti-TNF alfa

Gráfico 5: Distribuição dos doentes com DC segundo o tempo de diagnóstico e a história prévia de cirurgia abdominal dos doentes tratados com anti-TNF alfa

Gráfico 6: Distribuição dos doentes com DC segundo a melhora clínica com o tratamento com anti-TNF alfa em relação ao tempo de diagnóstico e história prévia de cirurgia abdominal

Gráfico 7: Distribuição dos doentes com DC segundo a piora clínica ou resultado inalterado com o tratamento com anti-TNF alfa em relação ao tempo de diagnóstico e história prévia de cirurgia abdominal

Gráfico 8: Distribuição dos doentes com DC segundo o uso concomitante de prednisona e anti-TNF alfa até a quinta dose.

Gráfico 9: Distribuição dos doentes com DC tratados com anti-TNF alfa segundo o valor médio do IADC 


\section{RESUMO}

Malheiros APR. Resultado do tratamento da doença de Crohn com anti-fator de necrose tumoral [dissertação]. São Paulo: Faculdade de Medicina, Universidade de São Paulo; 2008. 58p.

A doença de Crohn é uma inflamação crônica do trato gastrointestinal. O tratamento convencional é muitas vezes desapontador. Apesar da variedade de drogas disponíveis para o tratamento da doença inflamatória intestinal, tais como: salicilatos e seus derivados, corticosteróides, antibióticos e imunossupressores, nenhuma destas mostrou ser totalmente eficaz ou definitiva para o tratamento da doença e seus surtos de exacerbação. Pesquisas têm sido desenvolvidas com o objetivo de apresentar drogas mais efetivas. Dentre estas, destacam-se as drogas biológicas. O infliximabe é um anticorpo monoclonal quimérico anti-fator de necrose tumoral alfa e está indicado na doença de Crohn refratária e fistulizante. O objetivo deste estudo visa avaliar prospectivamente os resultados e efeitos colaterais precoces e tardios do uso do antiTNF alfa no tratamento de 60 doentes com doença de Crohn, no período de julho de 1999 a dezembro de 2005. Os doentes foram tratados com anti-TNF alfa (infliximabe), na dose de $5 \mathrm{mg} / \mathrm{kg}$ de peso, aplicado por via endovenosa em intervalos de dois meses. A avaliação foi realizada por protocolo clínico que classificava os quesitos: estado geral, sintomas intestinais e doença perianal em melhor, inalterado e pior, e pelo índice de atividade da doença de Cronh. Os doentes tratados com anti-TNF alfa apresentaram mediana de duração da doença de sete anos, variando de um a 28 anos entre a data do início dos sintomas e a data de início da pesquisa. 34 doentes (56,7\%) já haviam sido submetidos a uma ou mais operações abdominais e 38 (63,3\%) a operações orificiais. O software utilizado para a realização dos cálculos foi o SPSS ${ }^{\circledR} 9.0$ for Windows ${ }^{\mathrm{TM}}$, sendo estatisticamente significantes os testes com $\mathrm{p}<0,05$. Foram aplicadas 225 doses de anti-TNF alfa, em média, 3,7 doses por paciente num período de aproximadamente cinco anos, variando de uma a 14 doses. No tratamento inicial $76 \%$ dos pacientes responderam a droga. As principais indicações para o emprego do anti-TNF alfa foram a presença de doença perianal em 36 casos (60\%) e a intratabilidade clínica em 24 casos (40\%). Observou-se que após a primeira dose da medicação, os doentes com mais de dez anos de doença e submetidos à operação abdominal tiveram resultado satisfatório semelhantemente aqueles doentes com menos de cinco anos de doença e não operados com $\mathrm{p}<0,05$. O índice de atividade da doença de Crohn foi em média de 189,7 antes do início do tratamento e na primeira aplicação diminuiu em média para 135,4, e progressivamente ao longo das aplicações $(115,102,109$ e 88,4 até a quinta dose), sendo o resultado estatisticamente significativo. Houve efeito colateral em 40 aplicações $(17,8 \%)$, sendo os efeitos principais: eritema cutâneo, dispnéia e dor abdominal. O tratamento com anti-fator de necrose tumoral alfa, obedecidas as indicações precisas, associou-se a baixo índice de efeitos colaterais graves tendo apresentado bons resultados na resolução da doença de Crohn perianal, na melhora da sintomatologia intestinal e no estado geral dos pacientes. 


\section{SUMMARY}

Malheiros APR. Outcomes in the treatment of Crohn's disease with anti tumor necrososis factor-alpha [dissertation]. São Paulo: "Faculdade de Medicina, Universidade de São Paulo"; 2008. 58p.

Crohn's disease is a chronic inflammatory disorder of the gastrointestinal tract. Conventional treatment is many times disappointing. Besides the great number of available medications to treat inflammatory bowel diseases, such as salicilates and derivatives, corticosteroids, antibiotics and immunosuppressive agents, none of them proved to be totally efficient or the ultimate treatment for inflammatory diseases and their exacerbation. Researches have been carried out to find more effective therapeutic drugs. Among these therapeutics, biologic treatments have been in evidence. Infliximab is a chimeric IgG1 monoclonal antibody against tumor necrosis factoralpha, and is indicated for refractory luminal and fistulizing Crohn's disease. The aim of this study is to prospectively evaluate the outcome, early and late adverse events, in 60 patients diagnosed with Crohn's disease and treated with infliximab between July 1999 and December 2005. All patients were treated with anti-TNF-alpha (infliximab), $5 \mathrm{mg} / \mathrm{kg} /$ dose, intravenously, each two months. Patients were clinically evaluated using a protocol that classified the evolution of the health status, intestinal symptoms and perianal disease, as better, worse or unchanged, during the treatment. Crohn's disease activity index was also evaluated. Patients treated with anti-TNF-alpha presented a median disease duration of seven (range 1-28) years, between the beginning of the disease symptoms and the beginning of the research protocol. Thirty-four patients (56.7\%) have been submitted to one or more abdominal surgeries before, and 38 (63.3\%) to anal-rectum surgeries. All statistics tests were performed with computer software Statistical Package for the Social Sciences (SPSS ${ }^{\circledR}$ 9.0) for Windows ${ }^{\mathrm{TM}}$, and p values of less than 0.05 were considered statistically significant. Totals of 225 antiTNF-alpha doses were administered. The mean doses administered per patient, in a period of approximately five years, were 3.7 (range 1-14) doses. After the initial treatment, $76 \%$ of the patients achieved a response. The most frequent indications for anti-TNF-alpha was perianal disease, occurring in 36 patients $(60 \%)$, and clinical failure to the conventional treatment, happening in 24 patients (40\%). After the first dose of anti-TNF-alpha, patients with more than 10 years of treatment and previously submitted to abdominal surgery presented a satisfactory outcome, similar to those with less than 5 years of disease and not submitted to surgery, $\mathrm{p}<0.05$. Crohn's disease activity index showed a mean index of 189.7 before treatment, that decreased to 135.4 after the first dose, and progressively decreased with the subsequent doses (means: 115, 102, 109 and 88.4, until the fifth dose, $\mathrm{p}<0.05$ ). Adverse events were reported in 40 administrations $(17,8 \%)$ from the total. The most prevalent adverse events were: rash, dyspnoea and abdominal pain. The treatment with anti-TNF-alpha, following precise indications, was associated with a low incidence of severe adverse events and presented good outcomes in the resolution of perianal Crohn's disease, improving intestinal symptomatology and patients' health status. 


\section{INTRODUÇÃO}


A doença de Crohn (DC) tem se transformado em alvo da atenção de epidemiologistas, clínicos e cirurgiões de várias especialidades, uma vez que, além das manifestações intestinais, associam-se manifestações extra-intestinais diversas, algumas de conseqüências mais graves que a própria doença intestinal.

Acomete principalmente a população adulta e jovem. Representa perda financeira importante para o Estado, pelos custos associados aos tratamentos clínico e cirúrgico. O doente freqüentemente interrompe os estudos ou pára de trabalhar. Há grande impacto sobre os relacionamentos familiar, social e sexual.

A DC freqüentemente se acompanha de manifestações perianais. Nesta situação o objetivo do tratamento clínico é evitar que se instalem complicações que determinem incontinência anal ${ }^{(29,66,68)}$ tornando válidas todas as tentativas de tratamento.

O tratamento convencional é muitas vezes desapontador. Apesar da variedade de drogas disponíveis para o tratamento da DII, tais como: salicilatos e seus derivados, corticosteróides, antibióticos e imunossupressores, nenhuma destas mostrou ser totalmente eficaz ou definitiva para o tratamento da doença e seus surtos de exacerbação.

Nos casos em que a doença se torna irresponsiva com as drogas convencionais, e sendo o tratamento cirúrgico não curativo, será preciso a manutenção de medicações como: imunossupressores e corticosteróides. Os doentes dependentes de corticosteróides poderão ter efeitos adversos tão deletérios quanto a própria doença, como a ocorrência de osteopenia, catarata, insuficiência renal, hipertensão arterial entre outros. 
A cura da DC permanece ainda desconhecida, assim como as razões para a sua multiplicidade de manifestações clínicas intestinais e extra-intestinais. O tratamento é um grande desafio na área médica, já que uma vez estabelecido o diagnóstico, o doente deverá receber medicação em caráter permanente.

Muitas pesquisas têm sido desenvolvidas com o objetivo de desenvolver drogas mais efetivas. Dentre estas, destacam-se as drogas biológicas.

Sabe-se hoje que a integridade do corpo é mantida pelo funcionamento adequado do sistema imunológico. Na superfície intestinal existe a produção de anticorpos IgA pelos imunócitos, conferindo proteção ao órgão sem, no entanto, causar inflamação à sua parede. Quando esse mecanismo de defesa não é suficiente para conter o agente agressor, uma segunda linha de defesa é ativada através de anticorpos do tipo IgG, mediada pelos linfócitos Th1 ${ }^{(26,59)}$. Outros agressores como parasitas intestinais não são erradicados nem pela IgA nem pela IgG e envolvem uma resposta Th2IgE.

Na doença inflamatória intestinal, a resposta imune IgG é deflagrada sem que se identifique um agente agressor específico. Como a patogênese permanece desconhecida, uma forma de abordar a doença seria atuando sobre os mecanismos envolvidos no processo da inflamação intestinal sobre cuja compreensão tem-se obtido progresso considerável. O papel exercido pelas células T tem se tornado evidente com os estudos de modelos animais e na prática clínica. Em particular, as respostas das células T helper Th1 CD4+ com resultante secreção de interferon-gama, interleucina 1 beta e fator de necrose tumoral alfa parecem constituir um caminho regulador central ${ }^{(5)}$. 
O fator de necrose tumoral (TNF) alfa é uma citocina Th1 e exerce papel importante na DC. É produzida por monócitos, macrófagos e células T que podem afetar a proliferação, diferenciação e função de virtualmente qualquer célula ${ }^{(18,36)}$.

O TNF alfa tem largo espectro de efeitos biológicos relevantes na DII ${ }^{(25,71)}$ :

1. Ativa macrófagos residentes e promove a liberação de outros mediadores pró-inflamatórios, incluindo óxido nítrico, prostaciclina e fator ativador de plaquetas.

2. Induz a expressão de moléculas de adesão no endotélio vascular, favorecendo o influxo de novas células inflamatórias na mucosa.

3. Contribui para a lesão intestinal por alterar diretamente a integridade das membranas epiteliais.

A liberação de TNF alfa pelos monócitos e linfócitos T é mediada por metaloproteinase específica (TNF alfa convertase, TACE). Se o TACE for inativado, o TNF alfa não pode ser secretado e permanece biologicamente inativo ${ }^{(8,42)}$. Após a secreção, o TNF alfa liga-se como ligante solúvel a dois receptores transmembrana, TNF-R1 e TNF-R2, expressos por vários tipos celulares.

Há evidência que na patogênese da doença inflamatória intestinal há um desequilíbrio entre secreção e inibição do TNF alfa. ${ }^{(45)}$. Sabe-se que o TNF está elevado nas fezes, mucosa e sangue dos doentes com DC.

Estratégias com o objetivo de bloquear o TNF alfa foram desenvolvidas, algumas com potente atividade clínica, confirmando papel do TNF alfa na patogênese da DC e no tratamento de doentes de difícil manejo clínico ${ }^{(18,56,64)}$. 
Entre os variados tipos de anti-TNF alfa que surgiram para o tratamento da DC, podemos citar: infliximabe, adalimumab, CDP870, CDP571, etanercept e ornecept ${ }^{(56)}$.

O infliximabe é um anticorpo monoclonal IgG1 quimérico constituído de 75\% de proteína humana e $25 \%$ de proteína de camundongo. A porção de camundongo contém o sítio de ligação para o TNF alfa, enquanto a porção humana é responsável pela função efetora. O infliximabe liga-se ao TNF alfa solúvel e TNF ligado à membrana bloqueando as atividades biológicas da citocina ${ }^{(11,12)}$. Ele limita a resposta inflamatória de monócitos expostos a agentes bacterianos e proporciona a autoregulação destas citocinas pro-inflamatórias.

Estudos clínicos têm demonstrado que a inibição do TNF alfa é efetiva no tratamento da DC e mais recentemente retocolite ulcerativa (RCU), podendo estabelecer melhora do quadro clínico e/ou remissão dos sintomas intestinais e a cicatrização de feridas perianais ${ }^{(32,56,58,63)}$. 
2. OBJETIVOS 
O presente estudo visa avaliar prospectivamente os resultados e efeitos colaterais precoces e tardios do uso do anti-TNF alfa no tratamento dos doentes com doença de Crohn. 
3. MÉTODOS 
O estudo foi prospectivo avaliando-se 60 doentes com DC com idades entre 14 e 60 anos (mediana de 34 anos), sendo 33 do sexo feminino e 27 do sexo masculino, atendidos no Ambulatório de doenças inflamatórias do Serviço de Cirurgia do Cólon e Reto da Divisão de Clínica Cirúrgica II do Hospital das Clínicas da Faculdade de Medicina da Universidade de São Paulo (HCFMUSP), no período de julho de 1999 a dezembro de 2005. A distribuição dos doentes segundo idade e sexo figura no gráfico 1. O anti-TNF alfa utilizado neste trabalho foi o infliximabe.

Gráfico 1: Distribuição dos doentes com DC segundo a idade e sexo que foram tratados com anti-TNF alfa

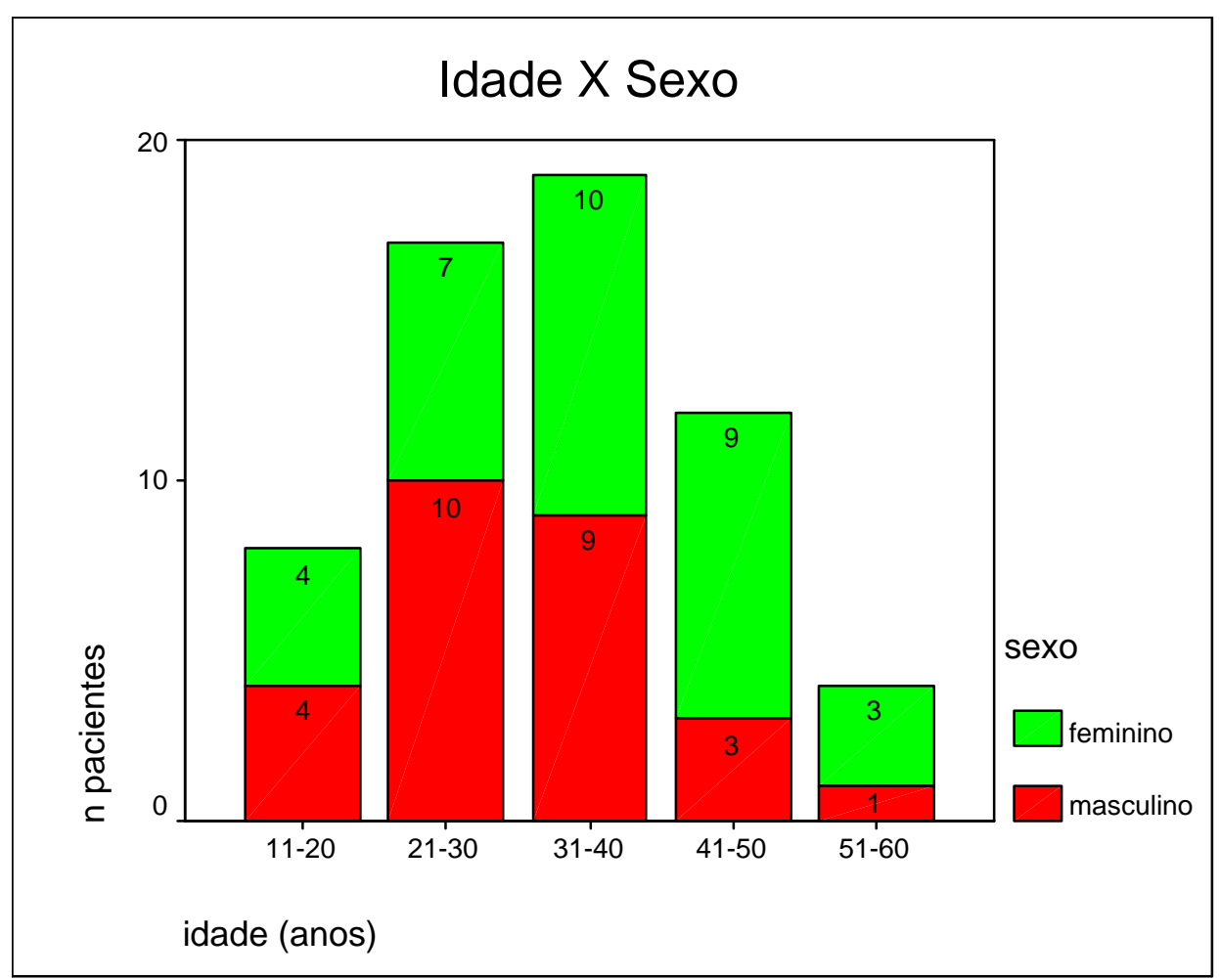


O projeto de pesquisa foi aprovado pelo Comitê de Ética desta Instituição e obteve-se consentimento informado por escrito de todos os doentes (Anexo A).

Os critérios de inclusão no estudo dos doentes com DC foram os seguintes:

1. DC em intestino delgado, intestino grosso e/ou fístulas perianais altas tratadas previamente com sedenho;

2. DC perianal, incluindo, úlcera, fissura e/ou fístulas baixas;

3. DC com intratabilidade clínica e/ou dependente de corticosteróides;

Foram considerados como critérios de exclusão:

1. Doentes com infecção atual ou nos últimos três meses;

2. Doentes com diagnóstico de tuberculose;

3. Doentes com quadro clínico e/ou radiológico de oclusão intestinal parcial ou total;

4. Doentes grávidas e/ou em período de amamentação;

Os doentes foram tratados com anti-TNF alfa (infliximabe), na dose de $5 \mathrm{mg} / \mathrm{kg}$ de peso, aplicado por via endovenosa a intervalos de dois meses, no Hospital Dia do HCFMUSP em período de, no mínimo, duas horas de infusão, sob supervisão de um profissional médico do próprio Hospital Dia.

Nos casos em que houve reação adversa foi instituído tratamento com 100mg de hidrocortizona endovenosa e/ou prometazina intramuscular, além do aumento do intervalo de infusão da droga. Nos casos graves, a infusão foi suspensa imediatamente. A alta hospitalar foi dada após o término do procedimento e o retorno no ambulatório de DII do HCFMUSP foi agendado bimestralmente. 
É protocolo no HCFMUSP, a realização de radiografia do tórax, leucograma e intradermo reação para tuberculose em todos os doentes que irão ser submetidos ao tratamento com anti-TNF alfa, assim como, é a recomendação da própria Secretaria de Saúde de São Paulo, portaria número 858, de 4 novembro de 2002.

Adotou-se como critério para interrupção do tratamento com o anti-TNF alfa:

1. Doentes que pioraram após a aplicação do anti-TNF alfa;

2. Doentes que permaneceram inalterados por duas aplicações consecutivas;

3. Doentes que tiveram efeitos colaterais importantes apesar do benefício da medicação, mas que não justificasse o risco do seu uso no tratamento da doença.

As medicações de uso oral e diário dos doentes foram mantidas durante o tratamento com o anti-TNF alfa de acordo com as orientações do médico responsável.

A avaliação foi realizada através de protocolo clínico (Anexo B) e exames laboratoriais de controle para todos os doentes. Os exames laboratoriais realizados antes e após cada aplicação foram: hemograma completo (hemoglobina e hematócrito), leucograma, PCR, VHS, uréia, creatinina, glicose, amilase, TGO, TGP, bilirrubinas totais e frações.

O índice de atividade da doença de Crohn, IADC (anexo C) foi mensurado naqueles doentes não portadores de estomia, antes e após cada dose do anti-TNF alfa ${ }^{(51)}$.

Considerou-se doença grave IADC maior ou igual a 400, e doença ativa em remissão e/ou melhora clínica satisfatória aqueles com IADC menor que 150 ou diminuição de 70 pontos do IADC pré anti-TNF alfa ${ }^{(14)}$. 
Na análise dos dados, os doentes foram divididos em três grupos de acordo com o tempo de doença, isto é, grupo 1 aqueles com até cinco anos de diagnóstico de DC, grupo 2, com seis até dez anos de diagnóstico de DC, e grupo 3 com mais de dez anos de diagnóstico de DC.

Foram avaliados os seguintes quesitos:

1. Localização da DC, incluindo: doença em intestino delgado (ID), intestino grosso (IG) e doença perianal (PA).

2. Tempo de doença, incluindo o tempo de diagnóstico de DC até a data de início da pesquisa em anos;

3. Presença de cirurgia abdominal e/ou orificial prévia ou concomitante ao uso do anti-TNF alfa.

4. Indicações para o uso do anti-TNF alfa (indicação principal e secundária);

5. Uso concomitante de outras drogas e quais drogas;

6. Número de infusões realizadas e intervalo de tempo entre as doses;

7. Resultados em relação ao estado geral do doente (sensação de bem estar, avaliação de artralgia e quaisquer manifestações que interfiram na qualidade de vida em relação à DII), considerando-se três possibilidades de resposta: melhor, inalterado ou pior;

8. Resultados em relação aos sintomas intestinais (número de evacuações, consistência das fezes, presença de sangramento e/ou muco nas fezes, dor abdominal), considerando-se as respostas: melhor, inalterado ou pior; 
9. Resultados em relação à doença perianal (presença de fístula, fissura, úlcera, dor perianal, secreção perianal), através da realização de exame proctológico, considerando-se como resposta: melhor, pior e inalterado;

10. IADC antes e após o tratamento com anti-TNF alfa, exceto naqueles que tinham ostomia;

11. Presença de efeitos colaterais precoces (febre, calafrios, prurido, urticária, dor torácica primária, hipotensão, dispnéia, mialgia, artralgia, erupção cutânea, edema facial, em mãos ou lábios, disfagia, dor de garganta, cefaléia e outros);

12. Presença de efeitos colaterais tardios (infecção viral, febre, abscesso, celulite, monilíase, sepse, comprometimento da cicatrização, infecção bacteriana, infecção fúngica, auto-anticorpo, síndrome “lupus-símile”, anormalidade do fator complemento, anemia, leucopenia, linfadenopatia, linfocitose, linfopenia, neutropenia, trombocitopenia, depressão, confusão, agitação, amnésia, apatia, nervosismo, sonolência, vertigem, cefaléia, conjuntivite, endoftalmite, ceratoconjuntivite, rubor, equimoses, hematoma, hipertensão, hipotensão, síncope, petéquias, tromboflebite, bradicardia, palpitação, vasoespasmo, cianose, isquemia periférica, arritmia, edema pulmonar, dor abdominal, obstipação, oclusão intestinal, função hepática alterada, colecistite, dermatite e alopecia, e outros);

13. Razões para interrupção do tratamento quando necessário e número de doses aplicadas antes da interrupção; 
Para análise estatística o teste de qui-quadrado de Pearson foi utilizado para verificar a existência da associação entre as variáveis categóricas: sexo, localização da doença, presença de cirurgias prévias, indicações principal e secundária, ostomia, uso de medicações associadas em cada dose, necessidade de anti-histamínico e analgesia durante a aplicação da droga, presença de efeitos colaterais precoces e tardios, avaliação do estado geral, sintoma intestinal e doença perianal após a aplicação. O teste de Mann-Whitney foi usado para comparar as variáveis numéricas: idade, número de doses, tempo de sintomatologia e diagnóstico, tempo de doença, IADC, intervalo de tempo entre as doses, em relação aos grupos: primeira dose até a dose 14 . O teste de Wilcoxon foi usado para comparação do IADC entre as doses e o teste Gama para comparação dos resultados entre as faixas etárias.

Para todos os testes foi utilizado um alfa de $5 \%$, sendo estatisticamente significantes os testes com $\mathrm{p}<0,05$. O software utilizado para a realização dos cálculos foi o SPSS ${ }^{\circledR} 9.0$ for Windows ${ }^{\mathrm{TM}}$. 
4. RESULTADOS 
A distribuição dos doentes com DC figura na tabela 1. Nenhum dos doentes estudados apresentou doença PA isoladamente como manifestação da DC.

Tabela 1: Distribuição dos doentes com DC segundo a localização da doença que foram tratados com anti-TNF alfa

\begin{tabular}{lcc}
\hline Localização da DC & doentes & \% doentes \\
\hline ID + IG +PA & 25 & 41,7 \\
ID + PA & 15 & 25 \\
IG + PA & 14 & 23,3 \\
ID & 3 & 5,0 \\
ID + IG & 2 & 3,3 \\
IG & 1 & 1,7 \\
\hline Total & 60 & 100 \\
\hline
\end{tabular}

Os doentes tratados com anti-TNF alfa apresentaram mediana de duração da doença de sete anos, variando de um a 28 anos entre a data do início dos sintomas e a data de início da pesquisa.

Nos grupos estudados de acordo com a duração da doença não encontramos diferença estatística significativa em relação à resposta ao tratamento após a primeira dose (Gráficos 2 , 3 e 4). 
Gráfico 2: Distribuição dos doentes com DC segundo o tempo de diagnóstico e o resultado do tratamento em relação ao estado geral dos doentes tratados com anti-TNF alfa

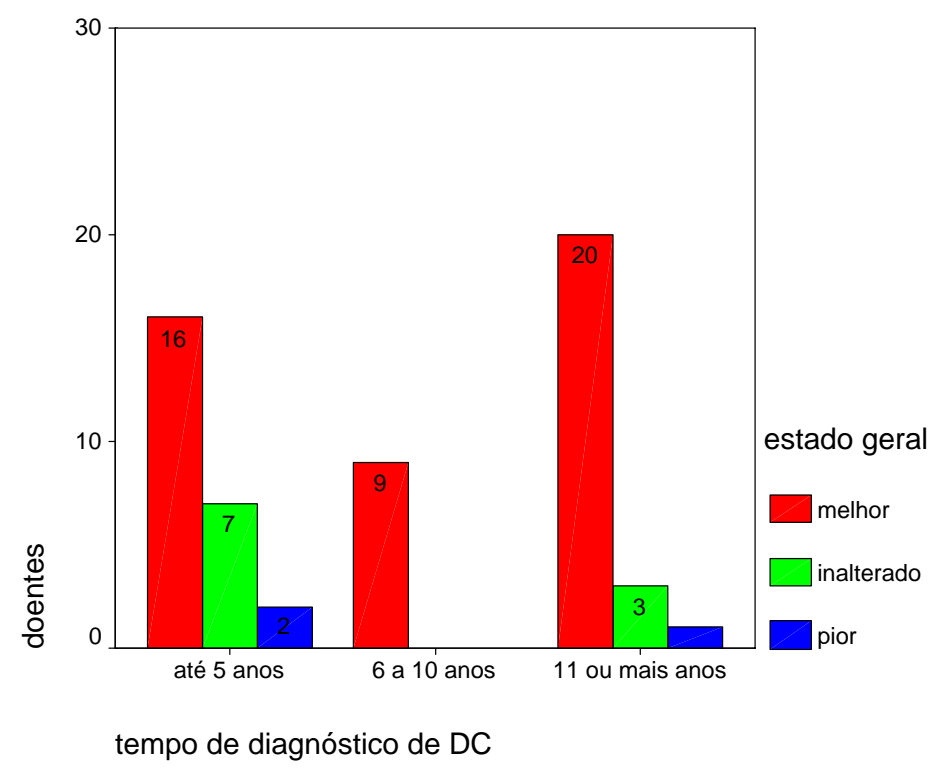

Gráfico 3: Distribuição dos doentes com DC segundo o tempo de diagnóstico e o resultado do tratamento em relação aos sintomas intestinais dos doentes tratados com anti-TNF alfa

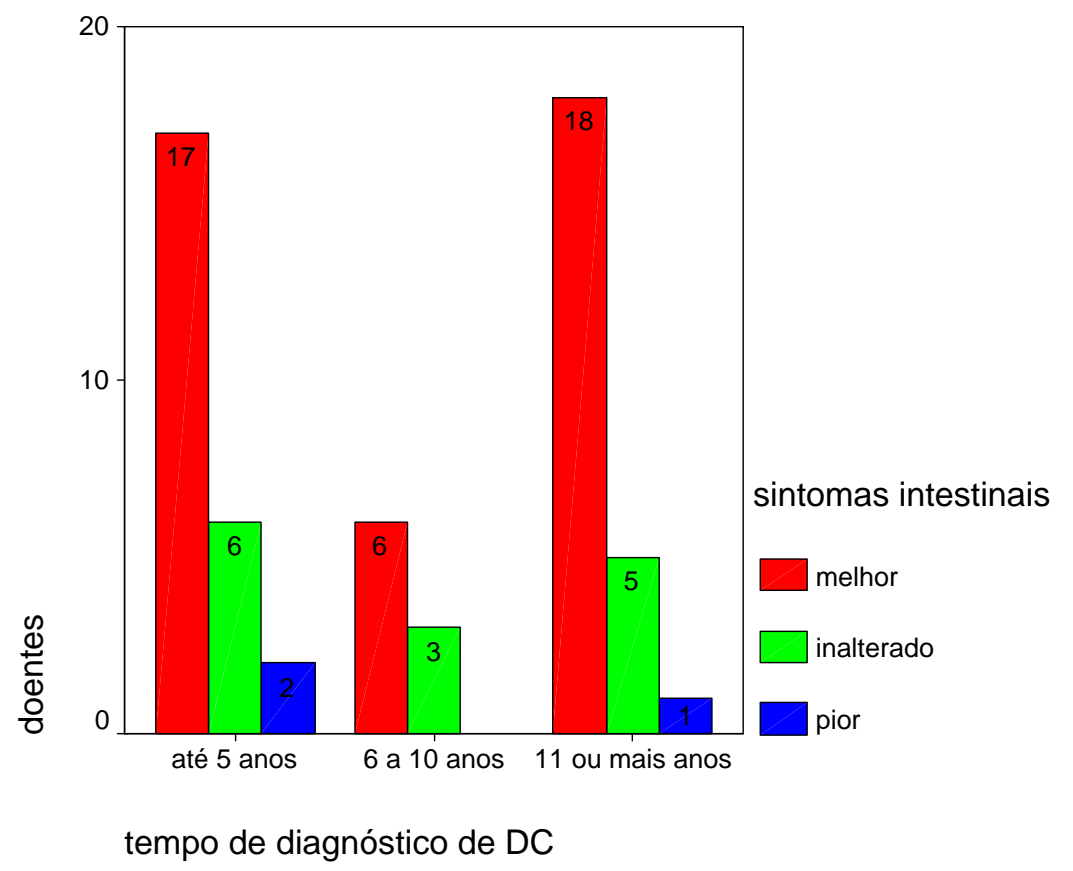


Gráfico 4: Distribuição dos doentes com DC segundo o tempo de diagnóstico e o resultado do tratamento em relação à doença perianal dos doentes tratados com antiTNF alfa

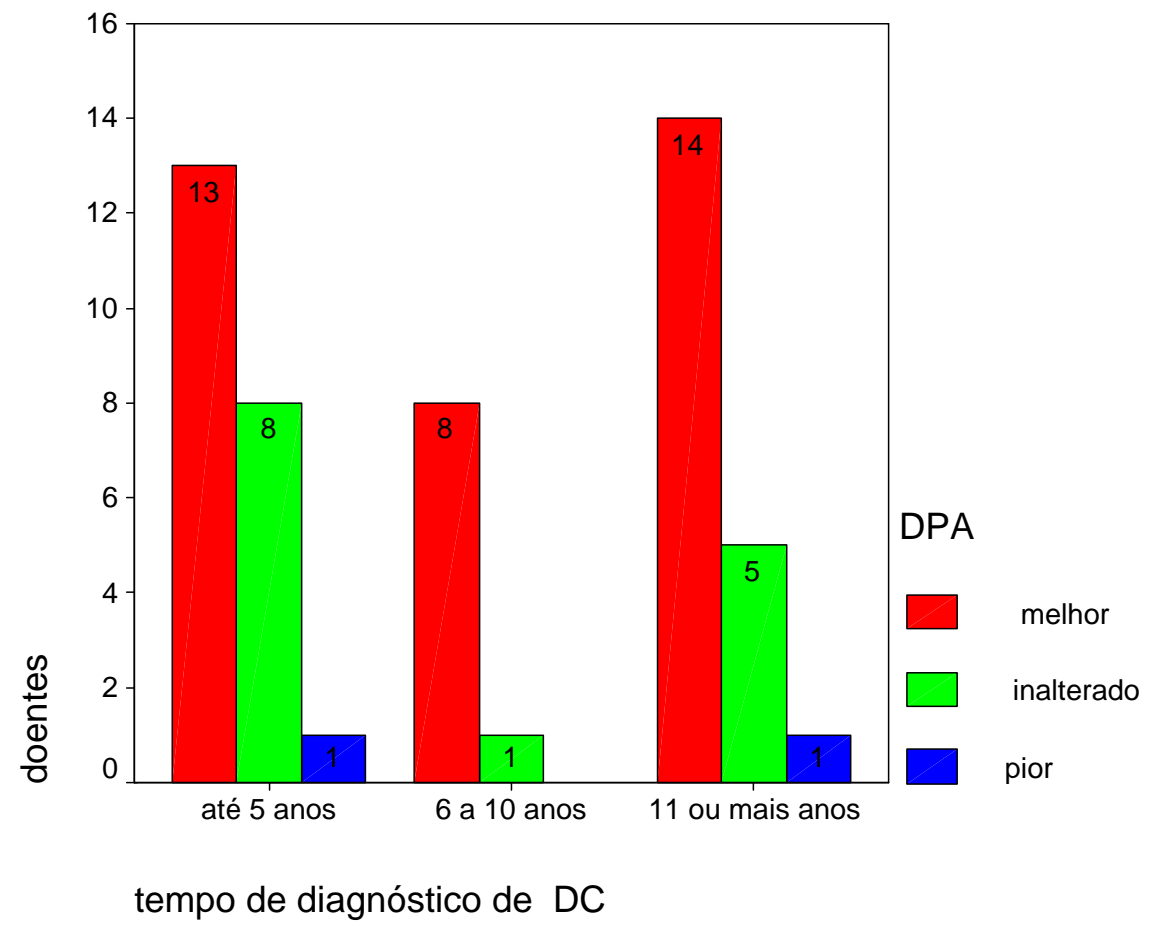

Nesta casuística, 34 doentes (56,7\%) já haviam sido submetidos a uma ou mais operações abdominais e $38(63,3 \%)$ a operações orificiais. As operações orificiais observadas no grupo estudado foram: colocação de sedenho para correção de fístula perianal, drenagem de abscesso, curetagem da lesão e aplicação local de corticosteróide. Os doentes submetidos a operações abdominais foram separados de acordo com o tempo de diagnóstico da DC como podemos observar no gráfico 5, sendo a diferença entre os grupos estatisticamente significativa $(p<0,05)$. 
Gráfico 5: Distribuição dos doentes com DC segundo o tempo de diagnóstico e a história prévia de cirurgia abdominal dos doentes tratados com anti-TNF alfa

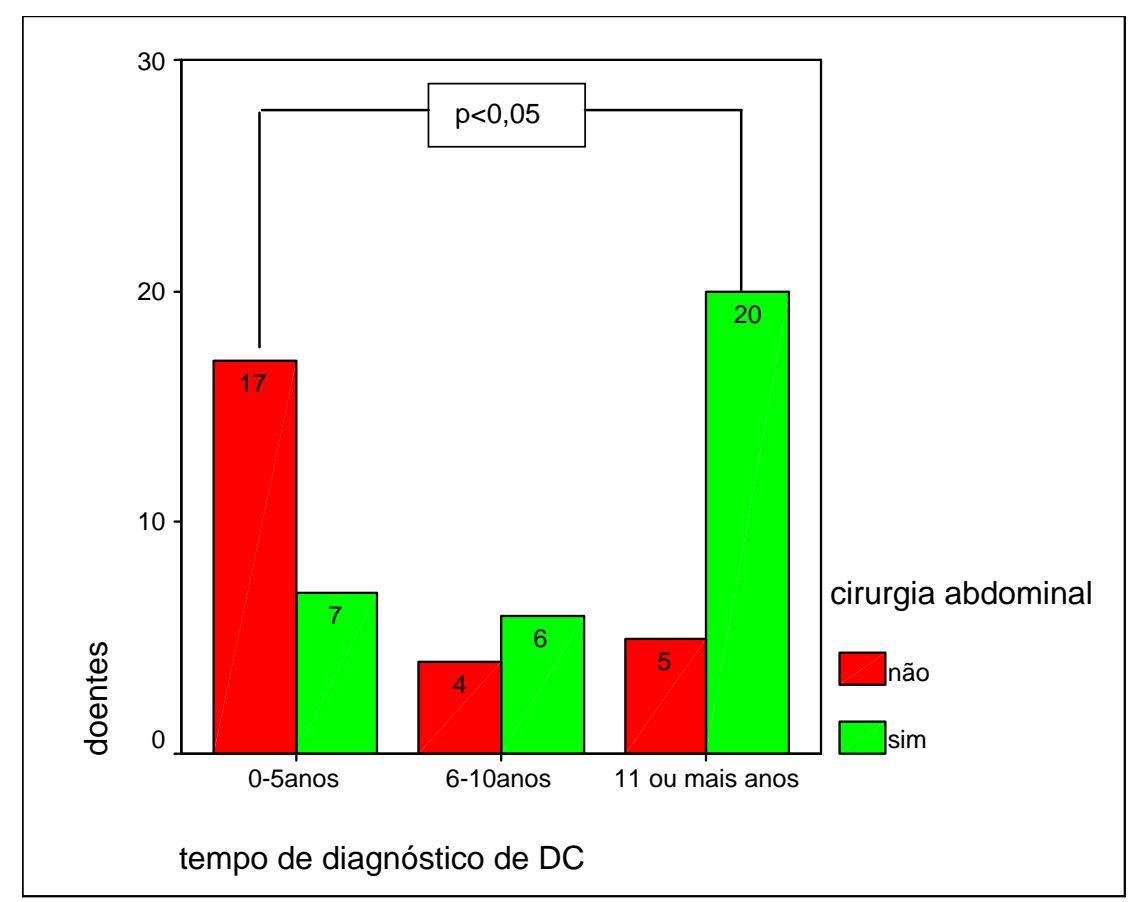

Observamos em relação aos resultados obtidos após a primeira dose da medicação, os doentes com mais de dez anos de doença e submetidos à operação abdominal tiveram resultado satisfatório semelhantemente aqueles doentes com menos de cinco anos de doença e não operados, como podemos observar nos gráficos 6 e 7, sendo este resultado estatisticamente significativo $(\mathrm{p}<0,05)$. 
Gráfico 6: Distribuição dos doentes com DC segundo a melhora clínica com o tratamento com anti-TNF alfa em relação ao tempo de diagnóstico e história prévia de cirurgia abdominal

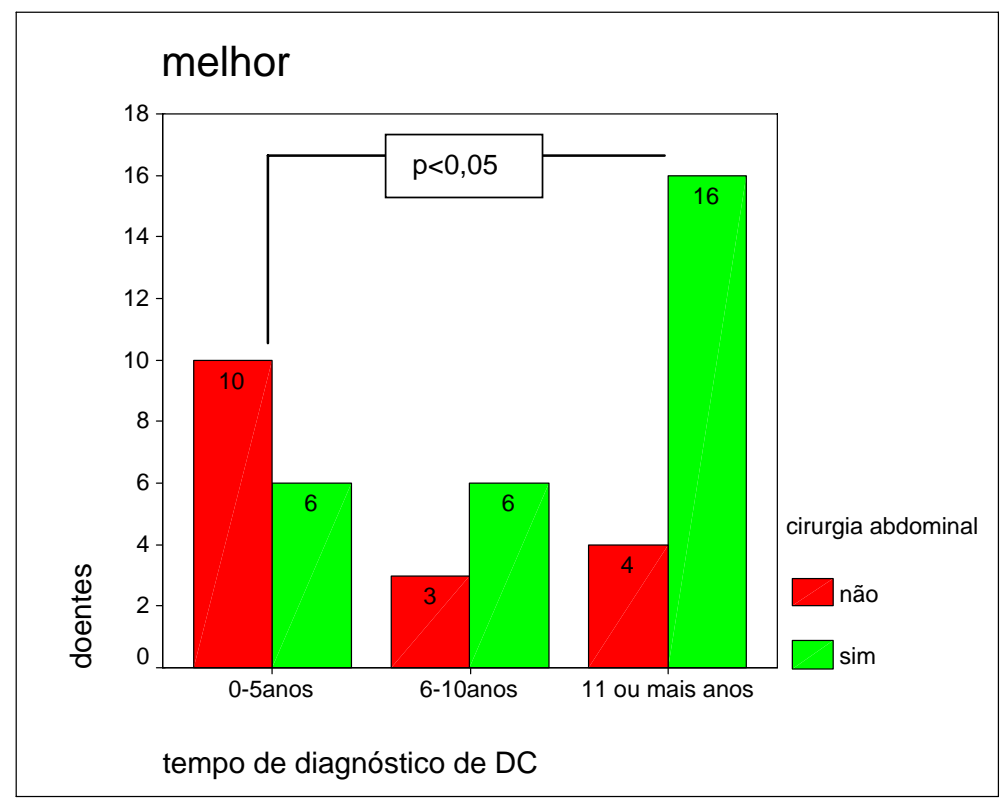

Gráfico 7: Distribuição dos doentes com DC segundo a piora clínica ou resultado inalterado com o tratamento com anti-TNF alfa em relação ao tempo de diagnóstico e história prévia de cirurgia abdominal

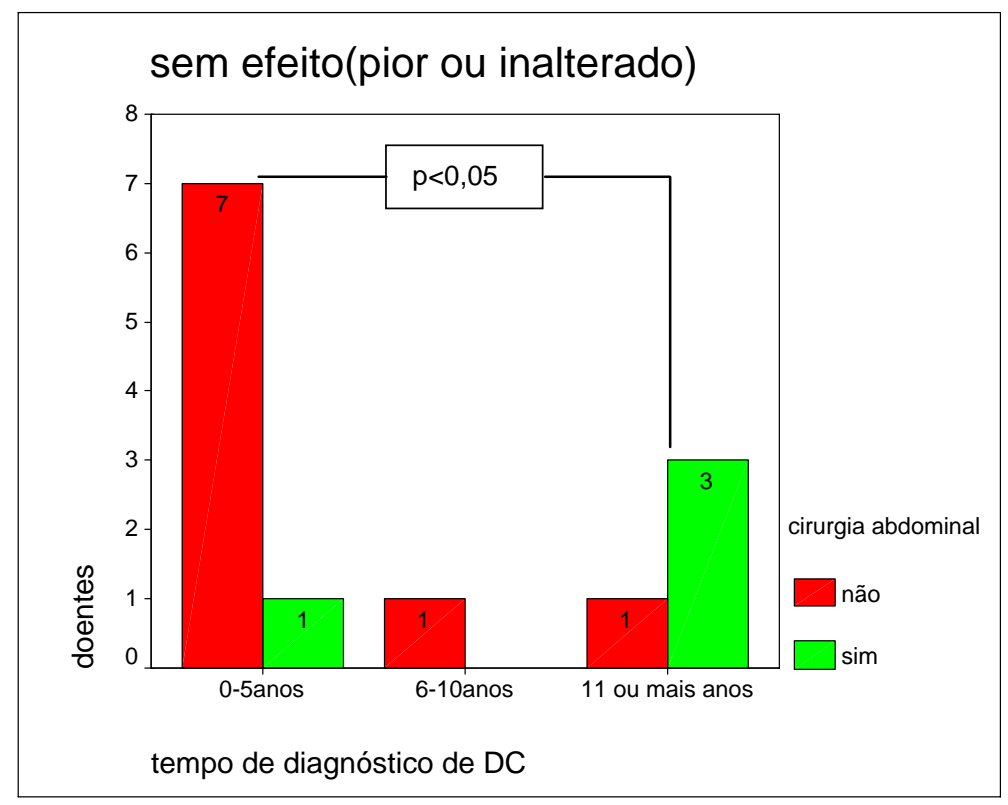


Dezesseis doentes $(26,7 \%)$ eram portadores de estomia definitiva em decorrência da DC.

A principal indicação para o emprego do anti-TNF alfa foi a presença de DPA em 36 casos (60\%) e a intratabilidade clínica em 24 casos (40\%). Em 19 casos (31,7\%) acrescentou-se uma segunda indicação para o uso da medicação. Destes, 15\% apresentavam artralgia importante como manifestação extra-intestinal da DC, 8,3\% apresentavam fístulas complexas (como por exemplo: fístula entero-vesical e enterocutânea), 3,3\% tinham DC periostomal e 1,7\% apresentou enterorragia não responsiva ao tratamento clínico convencional.

As principais drogas utilizadas concomitantemente ao anti-TNF alfa no tratamento clínico da DC foram: ciprofloxacino, prednisona, sulfassalazina e derivados 5-ASA, azatioprina e metronidazol. Todos os medicamentos foram prescritos de acordo com o quadro clínico e avaliação da evolução da lesão intestinal. Somente três doentes não utilizavam qualquer tipo de medicação na primeira dose do anti-TNF alfa, 11 utilizavam somente uma medicação, 18 duas medicações, 17 três medicações e 11 quatro medicações associadas, respectivamente, 5\%, 18,3\%, 30\%, 28,4\% e 18,3\%..

A distribuição dos doentes segundo as medicações associadas figuram na tabela 2. E a distribuição dos doentes que utilizaram prednisona até a quinta dose figura no gráfico 8. 
Tabela 2: Distribuição dos doentes com DC segundo as medicações associadas que foram tratados com anti-TNF alfa

\begin{tabular}{lcc}
\hline \multicolumn{1}{c}{$\begin{array}{c}\text { Dose } \\
\text { Drogas }\end{array}$} & Número de doentes & \% \\
\hline Ciprofloxacino & 40 & 66,7 \\
azatioprina & 40 & 66,7 \\
derivados 5-asa & 27 & 45,0 \\
prednisona & 25 & 41,7 \\
sulfassalazina & 6 & 10,0 \\
metronidazol & 4 & 6,7 \\
Nenhuma & 3 & 5,0 \\
\hline
\end{tabular}

Gráfico 8: Distribuição dos doentes com DC segundo o uso concomitante de prednisona e anti-TNF alfa até a quinta dose

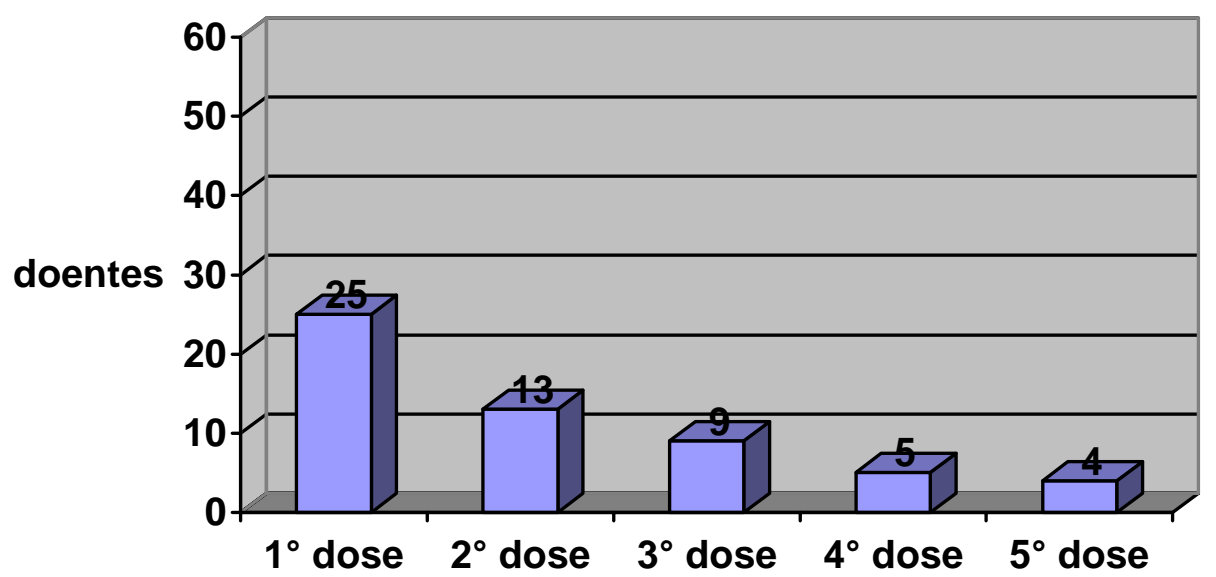


Foram aplicadas 225 doses de anti-TNF alfa, em média, 3,7 doses por doente num período de aproximadamente cinco anos, variando de uma a 14 doses (Tabela 3). O intervalo de tempo entre as doses aplicadas foi em média de oito semanas considerando-se que os doentes utilizaram a medicação de forma contínua.

Tabela 3: Distribuição dos doentes com DC segundo o número de doses aplicadas de anti-TNF alfa

\begin{tabular}{ccc}
\hline Número de aplicações & Número de doentes & \% \\
\hline 1 & 12 & 20,0 \\
2 & 11 & 18,3 \\
3 & 11 & 18,3 \\
4 & 10 & 16,7 \\
5 & 6 & 10,0 \\
6 & 3 & 5,0 \\
7 & 2 & 3,3 \\
9 & 2 & 3,3 \\
11 & 1 & 1,7 \\
13 & 1 & 1,7 \\
14 & 1 & 1,7 \\
\hline Total & 225 & \\
\hline
\end{tabular}

Na avaliação dos resultados pode-se observar que 46 doentes referiram melhora do estado geral já na primeira aplicação da medicação, dez permaneceram inalterados e três pioraram. Quanto à avaliação dos sintomas intestinais observamos que, na primeira dose, 42 doentes apresentaram melhora, 14 mantiveram-se inalterados e três pioraram. Dos 52 doentes com doença PA, 36 melhoraram na primeira aplicação, 14 mantiveram-se inalterados e dois pioraram. 
Todos os resultados referentes à avaliação do estado geral, sintomas intestinais e DPA figuram nas tabelas 4, 5 e 6 respectivamente.

Tabela 4: Distribuição dos doentes com DC segundo os resultados quanto à avaliação do estado geral em relação a cada aplicação que foram tratados com anti-TNF alfa

\begin{tabular}{lcccccccccccccc}
\hline $\begin{array}{l}\text { Aplicação } \\
\text { Resultado }\end{array}$ & $\mathbf{1}$ & $\mathbf{2}$ & $\mathbf{3}$ & $\mathbf{4}$ & $\mathbf{5}$ & $\mathbf{6}$ & $\mathbf{7}$ & $\mathbf{8}$ & $\mathbf{9}$ & $\mathbf{1 0}$ & $\mathbf{1 1}$ & $\mathbf{1 2}$ & $\mathbf{1 3}$ & $\mathbf{1 4}$ \\
\hline Melhor & 46 & 42 & 34 & 26 & 15 & 10 & 7 & 5 & 5 & 3 & 3 & 2 & 2 & 1 \\
Inalterado & 10 & 4 & 1 & 0 & 0 & 0 & 0 & 0 & 0 & 0 & 0 & 0 & 0 & 0 \\
Pior & 3 & 2 & 2 & 0 & 1 & 0 & 0 & 0 & 0 & 0 & 0 & 0 & 0 & 0 \\
\hline
\end{tabular}

Tabela 5: Distribuição dos doentes com DC segundo os resultados quanto à avaliação dos sintomas intestinais em relação a cada aplicação que foram tratados com anti-TNF alfa

\begin{tabular}{lcccccccccccccc}
\hline $\begin{array}{l}\text { Aplicação } \\
\text { Resultado }\end{array}$ & $\mathbf{1}$ & $\mathbf{2}$ & $\mathbf{3}$ & $\mathbf{4}$ & $\mathbf{5}$ & $\mathbf{6}$ & $\mathbf{7}$ & $\mathbf{8}$ & $\mathbf{9}$ & $\mathbf{1 0}$ & $\mathbf{1 1}$ & $\mathbf{1 2}$ & $\mathbf{1 3}$ & $\mathbf{1 4}$ \\
\hline Melhor & 42 & 37 & 31 & 23 & 13 & 9 & 7 & 5 & 5 & 3 & 3 & 2 & 2 & 1 \\
Inalterado & 14 & 10 & 5 & 3 & 1 & 1 & 0 & 0 & 0 & 0 & 0 & 0 & 0 & 0 \\
Pior & 3 & 1 & 1 & 0 & 2 & 0 & 0 & 0 & 0 & 0 & 0 & 0 & 0 & 0 \\
\hline
\end{tabular}

Tabela 6: Distribuição dos doentes com DC segundo os resultados quanto à avaliação da doença perianal em relação a cada aplicação que foram tratados com anti-TNF alfa

\begin{tabular}{lcccccccccccccc}
\hline $\begin{array}{l}\text { Aplicação } \\
\text { Resultado }\end{array}$ & $\mathbf{1}$ & $\mathbf{2}$ & $\mathbf{3}$ & $\mathbf{4}$ & $\mathbf{5}$ & $\mathbf{6}$ & $\mathbf{7}$ & $\mathbf{8}$ & $\mathbf{9}$ & $\mathbf{1 0}$ & $\mathbf{1 1}$ & $\mathbf{1 2}$ & $\mathbf{1 3}$ & $\mathbf{1 4}$ \\
\hline Melhor & 36 & 32 & 25 & 18 & 11 & 6 & 3 & 3 & 2 & 1 & 1 & 1 & 1 & 1 \\
Inalterado & 14 & 8 & 6 & 4 & 3 & 3 & 3 & 2 & 2 & 2 & 2 & 1 & 1 & 0 \\
Pior & 2 & 2 & 2 & 2 & 1 & 0 & 0 & 0 & 0 & 0 & 0 & 0 & 0 & 0 \\
\hline
\end{tabular}


A presença de efeitos colaterais graves ocorreu em cinco casos, sendo três casos de leucopenia, que necessitaram de interrupção do tratamento, um caso de oclusão intestinal em que o doente foi operado de urgência, e um caso de pneumonia em um doente com quadro grave de DC, em que o uso do infliximabe foi indicado como última opção de tratamento devido a gravidade do quadro clínico.

Houve efeito colateral em 40 aplicações (17,8\% dos casos). Não observamos efeitos colaterais após a sexta aplicação da medicação. Entre os efeitos colaterais precoces e tardios observamos: dispnéia (5 casos), eritema cutâneo (5 casos), dor abdominal (4 casos), leucopenia (três casos), febre (três casos), prurido (três casos), aumento de bilirrubinas em exames laboratoriais de controle (três casos), cefaléia (dois casos), alteração da pressão arterial (dois casos), formação de abscessos (dois casos), parestesia (dois casos), suboclusão intestinal (um caso), dor torácica (um caso), náusea (um caso), pneumonia (um caso), obstipação(um caso) e acne (um caso).

A avaliação dos doentes com o índice de atividade da doença de Crohn, IADC, foi em média de 189,7 antes do início do tratamento e na primeira aplicação diminuiu em média para 135,4, isto é, níveis de remissão da doença, sendo o resultado estatisticamente significativo. Houve diminuição contínua do valor do IADC ao longo das aplicações como pode ser verificado no gráfico 9. A avaliação estatística foi realizada até a quinta dose. Entre as doses a variação estatística do IADC também foi significativa com $\mathrm{p}<0,01$. 
Gráfico 9: Distribuição dos doentes com DC tratados com anti-TNF alfa segundo o valor médio do IADC

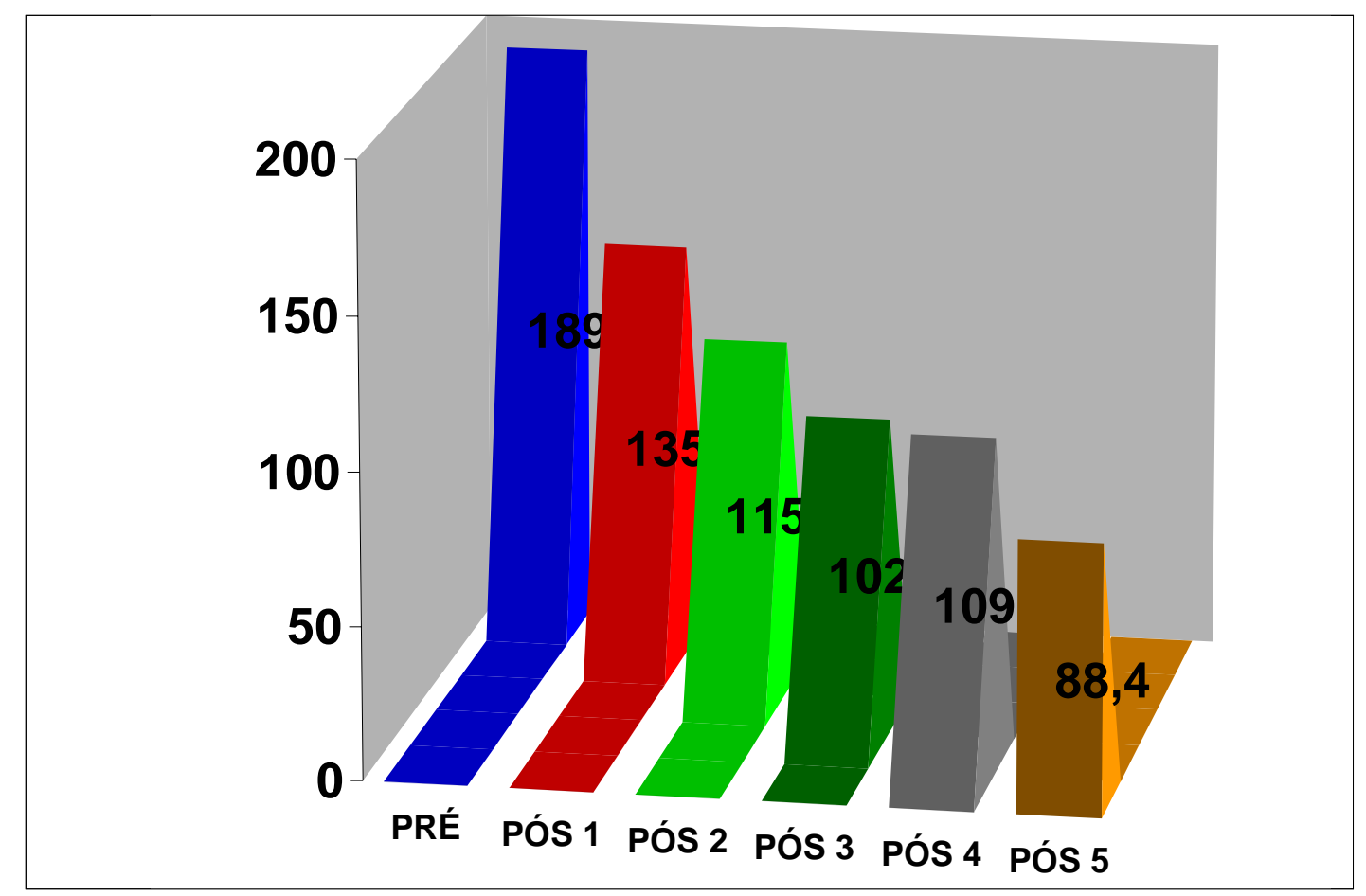

A droga foi suspensa por falta de resposta ou por não atender às expectativas propostas para o tratamento em 31 doentes, em média com 3,7 doses, variando de 1 a 14 doses. Treze doentes atingiram a estabilidade clinica e foi optado por suspender a medicação, em cinco casos houve efeitos colaterais que inviabilizaram o seu uso. Onze doentes desse grupo estudado permaneceram em tratamento com anti-TNF alfa a cada dois meses. 
5. DISCUSSÃO 
A doença de Crohn, primeiramente chamada de ileíte regional, foi descrita em 1932 por Crohn et al ${ }^{(14)}$. Desde esta época vários estudos têm sido realizados e desenvolvidos em busca da sua etiologia e cura.

A incidência da DC é relativamente incomum, variando de 0,08 a 7/1.000.000 habitantes na Europa ${ }^{(3)}$. Esses valores são variáveis de acordo com a localização geográfica, fatores socioeconômicos e ambientais. Tem sido observado o aumento significativo dos casos diagnosticados ao longo dos anos. Em nosso meio, este aumento na incidência pode ser deduzido pelo número crescente de publicações sobre a doença ${ }^{(1,2,4,9,10,13,15,21,22,23,27,28,39,43,51,53,54,55,62,69,73)}$.

O custo médio anual da DC estimado em estudo publicado em 2007 refere que $70 \%$ do valor gasto com o tratamento é representado pelo uso de medicamentos ${ }^{(17)}$.

O tratamento operatório nem sempre interrompe a progressão da doença e não é isento de complicações, principalmente quando localizada no intestino delgado e região perianal ${ }^{(52)}$. As taxas de complicações relacionadas à própria doença variam de 50 a 75\% e incluem a formação de fístulas, obstrução e cirurgia ${ }^{(44)}$.

Habitualmente o tratamento clínico da DC inicia-se com o uso dos salicílicos (sulfassalazina e derivados). No intestino grosso, a sulfassalazina é desdobrada pela ação bacteriana em sulfapiridina e 5-aminossalicílico (5-ASA), sendo a última de baixa absorção e o principal metabólito ativo do medicamento. Os principais mecanismos de ação do 5-ASA são a inibição de leucotrienos e de anticorpos, além da capacidade de assimilação de radicais livres. Na DC, doses de sulfassalazina entre três 
a 5g/dia induzem a remissão em aproximadamente $40 \%$ a $50 \%$ dos casos, principalmente na doença localizada no intestino grosso e nas formas que acometem o intestino delgado e grosso simultaneamente. A ação da droga é pouco melhor que o placebo, e as doses para manutenção são quase as mesmas utilizadas para indução do tratamento $^{(17,20)}$.

Os efeitos colaterais relacionados ao uso da sulfassalazina podem acometer até 45\% dos doentes, e estão relacionados aos altos níveis séricos da sulfapiridina e geralmente dose-dependentes. Os principais efeitos são: dor abdominal, cefaléia, náusea, vômito, anorexia, hemólise, infertilidade masculina entre outros ${ }^{(17,41,50)}$.

Os derivados salicílicos (5-ASA) foram desenvolvidos com a expectativa de minimizar os efeitos colaterais causados pela sulfassalazina com aumento da tolerância da droga em $80 \%$ a $90 \%$ dos casos. Doses superiores a 3,2g/dia são necessárias para o tratamento e manutenção na DC nas formas leves a moderadas, corroborando a dificuldade do tratamento clínico da doença ${ }^{(17,19,49)}$.

Outra droga de escolha nos casos graves a moderados é o corticosteróide. A droga tem ação rápida e pode ser administrada na forma oral, tópica e intravenosa. Em estudo populacional de 2001, os autores observaram que $44 \%$ dos doentes com DC ativa necessitaram de corticosteróides no controle da sintomatologia, e ao final de quatro semanas obtiveram melhora em $84 \%$ dos casos. Mas ao final de um ano, $28 \%$ deles tornaram-se córtico-dependentes e 40\% não responderam mais ao tratamento clínico necessitando de terapêutica cirúrgica ${ }^{(24)}$.

Os efeitos colaterais dos corticosteróides são bem conhecidos quando utilizados de modo prolongado: aumento do apetite e peso, edema, labilidade emocional, acne, psicose, hirsurtismo, osteoporose, osteonecrose, retardo do crescimento, catarata, 
insuficiência renal, supressão do eixo hipotálamo-hipófise-adrenal, glaucoma, miopatia, diabetes, infecção, hipertensão arterial e pancreatite aguda. Por esses motivos, o uso dos corticosteróides deve ser restrito e prescrito pelo menor período de tempo possível.

Sabe-se que alguns agentes bacterianos não específicos estão envolvidos na inflamação direta da mucosa intestinal na DC. Os antibióticos metronidazol e ciprofloxacino podem ser utilizados no tratamento das agudizações leves a moderadas e no tratamento de fístulas ${ }^{(47)}$. Eles diminuem a inflamação pela sua ação antibacteriana direta e, no caso do metronidazol e ciprofloxacino, agem com propriedades imunomoduladoras ${ }^{(49)}$.

No grupo dos imunomodulares, a azatioprina (AZA) e 6-mercaptopurina (6-MP) são as drogas mais utilizadas. Ambos são potentes imunossupressores que inibem a atividade dos linfócitos $\mathrm{T}$ e $\mathrm{B}$, além das células natural killer. Em doses maiores podem inibir a síntese das prostaglandinas. Seu uso na DC está indicado naqueles doentes córtico-dependentes e córtico-resistentes que não se beneficiam do uso prolongado dos corticosteróides, seja por sua ação ineficaz ou pelo excesso de efeitos colaterais cumulativos ao longo do tempo. Também estão indicados na diminuição de recorrência clinica e endoscópica pós-operatória ${ }^{(37)}$.

Os efeitos colaterais da azatioprina e 6-MP ocorrem em aproximadamente 15\% dos casos, e incluem: eritema cutâneo, dor abdominal, náuseas, entre os mais comuns, e principalmente leucopenia, neutropenia, trombocitopenia, anemia, infecções, alterações das enzimas hepáticas e neoplasias, efeitos estes mais preocupantes.

Em 1995, foi publicado um estudo populacional em doentes com DC em tratamento com drogas convencionais, incluindo a sulfassalazina e derivados, 
corticosteróides e imunossupressores. Os autores sugerem que 42\% dos doentes permanecerão assintomáticos por dois anos após o primeiro surto da doença, $12 \%$ permanecerão assintomáticos por dez anos, enquanto $10 \%$ permanecerão com a doença em atividade por dois anos consecutivos e 1\% por até dez anos. Em alguns casos serão necessárias várias operações para tratamento das complicações ${ }^{(52)}$.

Os objetivos do tratamento devem ser a remissão por longo prazo, diminuição do número e período de internações hospitalares e operações.

O resultado desapontador com as drogas habitualmente utilizadas estimulou o desenvolvimento de novos tratamentos com o objetivo de melhorar a qualidade de vida destes doentes. O principal avanço se constituiu na introdução no armamentário terapêutico da terapia biológica.

Em 1995, Van Dullemen et al ${ }^{(72)}$ sugeriram que o bloqueio do TNF alfa poderia ser a chave no tratamento da DC. Em 1997, Targan et al ${ }^{(64)}$ descreveram a eficácia do uso do anti-TNF como estratégia no tratamento da DC.

Lichetenstein et al, em 2004, já haviam descrito os benefícios do anti-TNF alfa principalmente na DC, como modulador do tratamento cirúrgico, demonstrando diminuição do número de hospitalizações e procedimentos operatórios de urgência ${ }^{(38)}$.

O primeiro anti-TNF alfa introduzido para uso na prática clínica nos Estados Unidos, em 1998, foi o infliximabe ${ }^{(37)}$. No Brasil, essa mesma medicação foi incluída pela Secretaria de Saúde Pública no tratamento da DC no ano de $2002^{(47)}$. Os resultados favoráveis com o uso desta medicação nos levaram a estudar seus resultados nos doentes tratados em nosso serviço.

O intervalo de tempo de diagnóstico da doença em nosso estudo não influenciou os resultados satisfatórios com o uso do anticorpo na primeira dose. No 
entanto, verificou-se que os melhores resultados situaram-se nos grupos com menos de cinco anos e com mais de dez anos de diagnóstico da doença.

As principais indicações descritas na literatura para o uso do infliximabe na DC são: DC moderada a grave refratária ao tratamento convencional apesar da terapia adequada com corticosteróides e/ou imunossupressores (AZA, 6-MP ou metotrexate), e DC fistulizante em doentes que não responderam adequadamente ao tratamento convencional, incluindo, antibióticos drenagem cirúrgica sob anestesia e imunossupressores ${ }^{(35,37,47)}$.

No nosso grupo as indicações mais freqüentes foram a DPA e intratabilidade. Em relação as fístulas, procuramos separar as fístulas perianais das fístulas enterais. Não incluímos os doentes com fístulas entero-entéricas, por tratar-se geralmente de doentes que apresentavam associação com estenose importante, razão pela qual a droga não tem indicação. A distinção entre os diversos tipos de fístulas não é feita pela maioria dos autores o que acaba por comprometer os resultados obtidos. Regueiro et al demonstraram a diferença dos resultados entre os diversos tipos de fístula. Os melhores resultados foram obtidos nas fístulas perianais, seguidas das enterais e os piores resultados ocorreram com as fístulas retovaginais. Mesmo nos casos de fístulas perianais os melhores resultados ocorreram nos doentes previamente tratados com a colocação cirúrgica de sedenhos ${ }^{(48)}$.

Notamos que em aproximadamente um terço dos casos somaram-se outras indicações que reforçaram o uso do anti-TNF alfa.

Outra indicação benéfica do uso do anti-TNF alfa, e comprovada por nós, é a possibilidade de descontinuidade da corticoterapia, concordando com Hanauer et al 
(31). A possibilidade de interromper ou diminuir o uso de corticoterapia em doentes dependentes é um grande avanço no manejo do tratamento da DC.

O uso de agentes imunossupressores como a azatioprina, 6-MP ou metotrexato concomitante ao anti-TNF alfa era considerado benéfico e poderia diminuir a incidência de efeitos colaterais ${ }^{(17)}$. No nosso grupo, não houve diferença estatística significante em relação aos doentes que já usavam azatioprina ou não, considerando-se a incidência de efeitos colaterais e sucesso da resposta clínica. Por esta razão, consideramos desnecessário o uso concomitante de imunomoduladores associados a terapia biológica. Trabalhos mais recentes já demonstraram que o uso de imunomoduladores concomitantemente ao anti-TNF alfa não diminui a incidência de efeitos colaterais ou a ocorrência de auto anticorpos anti anti-TNF alfa como se pensava anteriormente, sendo o uso de tais agentes necessários apenas na terapia de demanda ${ }^{(70)}$.

Em 1997, Targan et al ${ }^{(63)}$ avaliaram o uso do anticorpo em 108 doentes com DC moderada a grave, em estudo duplo cego, e dividiram os doentes em quatro grupos com 25 a 28 doentes por grupo: o grupo 1 recebeu 5mg/kg/peso de cA2; o grupo 2 recebeu 10mg/kg/peso; o grupo 3 recebeu 20 mg/kg/peso; e o grupo 4 recebeu placebo. A resposta clínica adequada nesses doentes foi considerada de acordo com a redução do IADC de 70 pontos ou mais. Após quatro semanas, eles obtiveram sucesso de $81 \%$ no grupo $1,50 \%$ no grupo 2 , $64 \%$ no grupo 3 , e $17 \%$ no grupo 4 . Foi considerada remissão clínica em 48\% dos casos em comparação com 4\% do grupo placebo ( $p<0,001)$.

O mesmo autor, em 2000, observou que a indução do tratamento com anti-TNF alfa no regime de três doses (0,2,6 semanas) causou menor sensibilidade imunogênica e menor formação de anticorpos anti anti-TNF alfa que o uso isolado da medicação em 
doses esporádicas ${ }^{(64)}$. No grupo observado inicialmente no HCFMUSP optamos por questões econômicas no início da pesquisa em utilizar as doses a cada dois meses, e sem as doses de indução verificamos que os índices de sucesso foram semelhantes à literatura, que citam resposta clínica favorável em aproximadamente 65\% dos casos e remissão dos sintomas em torno de $33 \%{ }^{(31,57)}$, porém não estudamos a formação de anticorpo anti anti-TNF alfa.

Mais adiante, em 2002, foi publicado o maior e mais importante estudo multicêntrico randomizado envolvendo o infliximabe, o chamado ACCENT I. Este estudo fortaleceu a indicação do tratamento após demonstrar seus beneficios em 573 doentes, de 45 centros envolvendo: América do Norte, Europa e Israel. Foram randomizados três grupos de doentes que utilizaram doses diferentes da droga: grupo 1 que recebeu dose única do anticorpo (5mg/kg/peso), o grupo 2 que recebeu três doses de 5mg/kg/peso no intervalo de 0, 2 e 6 semanas e doses de manutenção de $5 \mathrm{mg} / \mathrm{kg} /$ peso a cada oito semanas até 46 semanas , e o grupo 3 que recebeu as mesmas três doses de indução do grupo anterior e manutenção com doses de 10mg/kg/peso a cada oito semanas até completar 46 semanas. Todos foram avaliados após o período de 54 semanas, e observou-se remissão da doença em 14\% do primeiro grupo, em 29\% do segundo grupo e 39\% do terceiro grupo, houve melhora clínica em 16\%, 38\% e $47 \%$ respectivamente neste mesmo período ${ }^{(31)}$.

O ACCENT II foi idealizado para demonstrar o impacto da terapia de manutenção a cada oito semanas, nos doentes com doença fistulizante e refratária. Neste, os autores observaram que a terapia de indução com doses nas semanas 0, 2 e 6 associada a manutenção do uso da droga a cada dois meses proporcionou a remissão 
clínica das fistulas em 46\% dos casos após 54 semanas em comparação com 23\% daqueles que não receberam a terapia de manutenção ${ }^{(57)}$.

A abordagem utilizada por nós nesse grupo inicial de sessenta doentes, revelou que a terapia de doses a cada oito semanas mostrou índices de sucesso no tratamento semelhantes aos estudos já publicados, quando avaliamos nossa casuística até a quinta dose. Observamos que em todos os três aspectos (estado geral, sintomas intestinais e doença perianal) houve melhora clínica superior a 60\%.

O IADC tem sido usado para avaliar a atividade da DC por mais de um quarto de século. Alguns índices como Harvey-Bradshaw ${ }^{(73)}$, Cape Town ${ }^{(51)}$ e suas variações foram revisadas e validadas para mensurar, seja objetivamente ou não, a atividade da doença ${ }^{(75)}$. A maioria dos trabalhos considera o IADC o instrumento mais factível para esse objetivo. Neste índice é considerada a análise de oito itens subjetivos mais o hematócrito (Anexo 2). Sabe-se que o índice não tem correlação com a extensão e localização da doença em seus diversos segmentos: intestino delgado, intestino grosso e perianal e suas combinações ${ }^{(65)}$. Porém, o IADC ainda é largamente utilizado nos diversos trabalhos e por isso tornou-se neste estudo fator de avaliação do nosso grupo.

Assim como nos estudos multicêntricos ${ }^{(31,57)}$ obtivemos, em média, índices de remissão da DC abaixo de 150 pontos após a primeira até a quinta dose com diferença estatística significativa em relação ao período antes do uso do anticorpo.

Os resultados obtidos devem ser considerados em prol de uma população em geral jovem, excluída muitas vezes precocemente do mercado de trabalho, tamanho o fardo da própria DC. São doentes sofridos com a perda da integridade física, psíquica e sexual, abalada pela auto-imagem destruída por várias cirurgias abdominais e trajetos fistulosos que adentram desde o períneo até a parede abdominal. 
Se considerarmos as vantagens do infliximabe tais como: o menor número de internações, exames múltiplos na fase ativa da doença e efeitos adversos pelo uso por longos períodos de outras drogas, como por exemplo, os corticosteróides, talvez estes benefícios superem os custos da medicação.

Inúmeras complicações infecciosas foram descritas conseqüentemente a imunossupressão relacionada com o uso do anti TNF alfa, tais como: tuberculose, listriose, histoplasmose entre outras ${ }^{(40,46,57,61)}$. Em 2004, Herrlinger et al ${ }^{(35)}$ relataram 44 complicações fatais após o uso do infliximabe na Alemanha, sendo 24 delas relacionadas a processo infeccioso grave, o que não ocorreu nesta casuística , devido aos cuidados na seleção dos doentes que foram cuidadosamente avaliados antes do início da medicação.

Sabe-se que o tratamento com o anti-TNF alfa diminui substancialmente o poder de defesa contra agentes bacterianos, tornando a imunossupressão potencialmente fatal em casos mais graves. Eventos como pneumonia por Pneumocystis carinni, complicações cutâneas infecciosas, leucopenia, neutropenia e pancitopenia foram relatados $(31,46,60,61)$.

A maioria dos trabalhos relatou freqüência de efeitos adversos graves em menos de $10 \%$. Os efeitos mais comuns observados atingem taxas de até 32\%, e são: aqueles relacionados a infusão, infecções de vias aéreas superiores, bronquite, faringite, febre, cefaléia, náuseas, dor abdominal, e os efeitos menos comuns são: tontura, dor torácica, artralgia, reações de hipersensibilidade tardia, abscessos (abdominais ou perianais), pneumonia, furunculose, obstrução intestinal, anemia hemolítica, alterações cardíacas, lúpus induzido por droga ${ }^{(31)}$. O risco de linfoma não Hodgkin é incerto, e deve ser relatado aos doentes antes do uso da droga ${ }^{(17,30)}$. 
Vale ressaltar, que a maioria dos efeitos colaterais por nós observados foram leves e não inviabilizaram o tratamento na maioria dos nossos casos. Com o passar dos anos e aquisição contínua de experiência no manejo da droga foi possível controle melhor desses efeitos adversos leves, sem a necessidade de suspensão da droga.

Nossos índices de sucesso com o uso da droga avaliados estatisticamente até o período de 32 semanas, com intervalos de oito semanas entre as doses, sem a aplicação das doses de indução (0, 2 e 6 semanas) foram semelhantes aos obtidos com os estudos multicêntricos apresentados ${ }^{(31,57)}$.

Apesar do tratamento não ser curativo da mesma forma que o tratamento convencional, o anti-TNF tem a vantagem, quando administrado em casos selecionados, de levar a resposta clínica rápida. Além disto, a droga proporciona a cicatrização das lesões intestinais, o que não é freqüente com a maioria dos medicamentos de uso convencional ${ }^{(34)}$.

Outra abordagem em relação ao anticorpo é a indicação primária da droga, antes mesmo da introdução de drogas menos complexas, como: aminossacilatos, corticosteróides, etc. Esta estratégia terapêutica é chamada de “top-down”, em que os doentes são medicados com imunomodulatores e agentes biológicos, no intuito de induzir respostas mais rápidas, remissão duradoura e tentar alterar a evolução natural da doença visando o bem estar do indivíduo portador da DC.

Em estudo realizado na Bélgica e Holanda, 129 indivíduos foram randomizados em dois grupos, aqueles que receberam corticoterapia convencional e aqueles que receberam o anti-TNF alfa, infliximabe, associado à azatioprina, como droga de primeira escolha. O resultados não foram estatisticamente significativos no período de doze meses, mas percebeu-se que os indivíduos tratados com os agentes biológicos 
alcançaram remissão clínica mais rapidamente e permaneceram sem sintomatologia por muito mais tempo, sem a necessidade de receber corticoterapia (75\% versus $48 \%$ ) no período de seis meses ${ }^{(16)}$.

Em 26 centros da Europa, foi realizado um estudo multicêntrico randomizado o qual demonstrou que o uso da terapia primária (ou “top down”) com o anti-TNF alfa em doentes recém diagnosticados ou com doença ativa há menos de quatro anos causou menor taxa de recidiva da DC, redução do uso de corticosteróide e período de ausência de sintomatologia significativamente maior quando comparado ao grupo que utilizou a terapia convencional. Os autores também relatam o desaparecimento de sinais de ulceração da mucosa em $73 \%$ dos doentes tratados com o anticorpo contra $30 \%$ dos que não utilizaram a terapia biológica ${ }^{(34)}$.

Em nosso estudo, verificamos que as melhores respostas ao uso de terapia biológica ocorreram no grupo com pouco tempo de duração da doença nos quais ainda não haviam se instalado as complicações (por exemplo, estenose), ou no grupo com mais de 10 anos de evolução. Este grupo era constituído em sua maioria por doentes já operados e, portanto, sem complicações da doença, ou seja, estavam se comportando como doentes em fase inicial da doença. Estes resultados corroboram a idéia de que o uso da terapia biológica como droga de escolha inicial seja benéfica para os doentes.

Esse tipo de abordagem não é consenso na prática clínica. Mais estudos são necessários para que possamos fundamentar tal medida terapêutica. 
6. CONCLUSÕES 
O tratamento com anti-fator de necrose tumoral alfa, obedecidas as indicações precisas, associou-se a baixo índice de efeitos colaterais graves tendo apresentado bons resultados na resolução da doença de Crohn perianal, na melhora da sintomatologia intestinal e no estado geral dos doentes. Os nossos resultados tendem a favorecer a terapia regressiva (“top-down”). 
7. ANEXOS 
Anexo 1 - Protocolo de pesquisa: Resultado do tratamento da doença de Crohn com Anti-fator de necrose tumoral alfa

$\mathbf{N}^{\circ}$ protocolo

Nome:

RG HC:

data nascimento:

$\mathrm{F}$

M

Cor:

Data diagnóstico:

Tempo de doença:

Localização

ID

IG

DPA

Outras doenças:

Cirurgias:

PA ABD

Dose

data

$N^{\circ}$ frascos

medicamento em uso

SULFA

PENTASA

METICORTEN

CIPRO

AZTIOPRINA

anti-hist

analg.

Ef. Colaterais:

Nenhum

febre

calafrio

cutâneo

hipotensão

dor torác.

falta de ar

Ef. Colaterais tardios:

Resultados(Melhor=M, Pior=P,inalterado=l)

Est. Geral

Sint intest

DPA

Intervalo

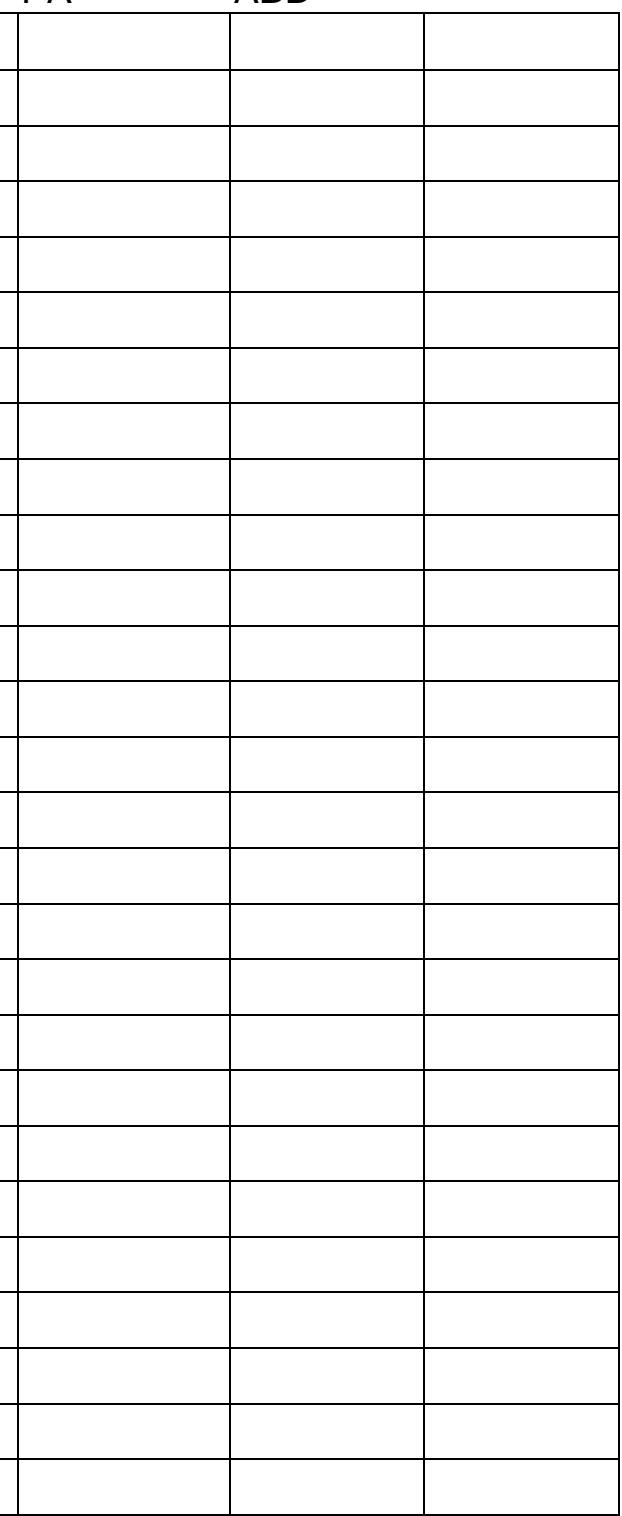




\section{Anexo 2 - Índice de atividade da doençca de Crohn}

\section{CDAI-INDICE DE ATIVIDADE DA DOENCA DE CROHN}

NONE: No. PROTOCOLO

1. Himeto de enacuaçöes liquidas \begin{tabular}{|l|l|l|l|l|l|l|} 
Dias 1 & 2 & 3 & 4 & 5 & & \\
\hline & & & & & & \\
\hline
\end{tabular} $\operatorname{soma} x$ fator $=$ subtotal

2. Dor abdominal (netihuma $=0$; discreta $=1$, moderadie2, intensa $=3$ )

3. Sengaço de bem estar

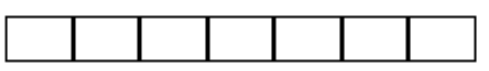
$\mathrm{x} 5=$ (getatnlmente berre [0, pouco alterada=1, fาuimo $=2$, muito tuifr= 3 , tertivel $=4$ )

4. O paciente apresenta agora

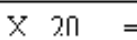

1- ARTRITE/ARTRALGLA

2- RITE/UVEITE

3- ERITEMA NODOSO/ PIODERMA GANGRENOSO, ESTOMA TITE

4- FISSURA ANAL/ FISTULA/ABSCESSO

5- OUTRASFISTULAS

6- FEBRE

$$
7-
$$

5. Tomando imosed anal gésico (nă $=0, \sin =1$ )

6. Massa abdominal (netihuma=0, questionà

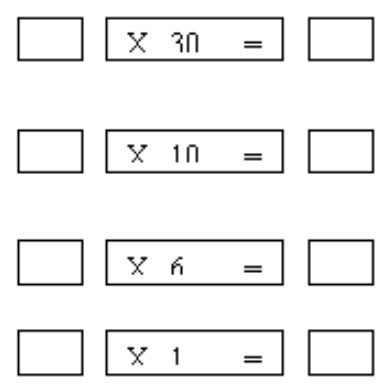

7. hematócrito (homem=47, mulher=42)

8. Peso $\square$ Feso padtăo (\%abaixo do peso padräo)

(\%oabara do pesa padtaio)

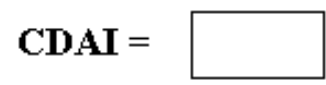




\section{Anexo 3 - Termo de consentimento}

\section{TERMO DE CONSENTIMENTO LIVRE E ESCLARECIDO}

(Instruções para preenchimento no verso)

\section{I - DADOS DE IDENTIFICAÇÃO DO SUJEITO DA PESQUISA OU RESPONSÁVEL LEGAL}

1. NOME DO DOENTE ...

DOCUMENTO DE IDENTIDADE No : SEXO : .MŽ F Ž

DATA NASCIMENTO: ..........

ENDEREÇO

BAIRRO: CEP: APTO:

2.RESPONSÁVEL LEGAL

NATUREZA (grau de parentesco, tutor, curador etc.) DOCUMENTO DE IDENTIDADE DATA NASCIMENTO.: ................... ENDEREÇO: $\mathrm{N}^{\mathrm{O}}$ SEXO: $M \check{Z} \quad F \check{Z}$

BAIRRO:

CEP: TELEFONE: DDD APTO: CIDADE: ...........

\section{II - DADOS SOBRE A PESQUISA CIENTÍFICA}

\section{RESULTADO DO TRATAMENTO DA DOENÇA INFLAMATÓRIA INTESTINAL} COM ANTI-FATOR DE NECROSE TUMORAL ALFA

2.PESQUISADOR: ANNA PAULA ROCHA MALHEIROS CARGO/FUNÇÃO: MÉDICA INSCRIÇÃO CONSELHO REGIONAL Nº .96.918 UNIDADE DO HCFMUSP: CIRURGIA DO APARELHO DIGESTIVO

3. AVALIAÇÃO DO RISCO DA PESQUISA:

$\begin{array}{llllll}\text { SEM RISCO } & \check{Z} & \text { RISCO MÍNIMO } & \mathbf{x} & \text { RISCO MÉDIO } & \check{Z} \\ \text { RISCO BAIXO } & \check{Z} & \text { RISCO MAIOR } & \check{Z} & & \end{array}$

(probabilidade de que o indivíduo sofra algum dano como consequência imediata ou tardia do estudo)

4.DURAÇÃO DA PESQUISA : DOZE MESES 


\section{III - REGISTRO DAS EXPLICAÇÕES DO PESQUISADOR AO DOENTE OU SEU REPRESENTANTE LEGAL SOBRE A PESQUISA CONSIGNANDO:}

Prezado doente, a doença de Crohn é um tipo de doença inflamatória intestinal que acomete o tubo digestivo desde a boca até o ânus, inclusive podendo levar a perda da continência para gases e fezes. Manifesta-se principalmente através de episódios de diarréia e formação de trajetos fistulosos do tubo digestivo até a pele, ou através de fístulas internas, pode ocorrer quadro de obstrução do intestino e dor abdominal, assim como, manifestações extra-inetinais, as quais não estão necessariamente relacionadas à maneira de evacuar, mas também fazem parte do quadro clínico da doença, como por exemplo: dor articular e manifestações cutâneas, febre e sensação de mal-estar, quadros de anemia e perda de sangue.

Dentre os tipos de tratamento, existe o tratamento com medicações, principalmente: os derivados salicilatos, corticosteróides, imunossupressores e drigas biológicas como o anti-Fator de Necrose Tumoral alfa (anti-TNF alfa), infliximabe, nome comercial REMICADE ${ }^{\circledR}$, além do tratamento através de cirurgia quando o doente não melhora com o uso das medicações.

$\mathrm{O}$ anti-Fator de Necrose Tumoral alfa (anti-TNF alfa), isto é, o infliximabe com nome comercial de REMICADE ${ }^{\circledR}$ é uma droga que atua no sistema defesa do doente, permitindo em muitos casos o fechamento das fístulas sem o tratamento cirúrgico e melhora do quadro clínico em outros. A medicação é administrada pela veia com internação do doente somente durante a aplicação do medicamento, que deverá ser supervisionado por profissional médico no local da aplicação. Os efeitos colaterais descritos com o uso da medicação são: efeitos colaterais precoces (febre, calafrios, prurido, urticária, dor torácica primária, hipotensão, dispnéia, mialgia, artralgia, erupção cutânea, edema facial, em mãos ou lábios, disfagia, dor de garganta, cefaléia e outros); efeitos colaterais tardios (infecção viral, febre, abscesso, celulite, monilíase, sepse, comprometimento da cicatrização, infecção bacteriana, infecção fúngica, auto-anticorpo, síndrome "lupus-like", anormalidade do fator complemento, anemia, leucopenia, linfadenopatia, linfocitose, linfopenia, neutropenia, trombocitopenia, depressão, confusão, agitação, amnésia, apatia, nervosismo, sonolência, vertigem, cefaléia, conjuntivite, endoftalmite, ceratoconjuntivite, rubor, equimoses, hematoma, hipertensão, hipotensão, síncope, petéquias, tromboflebite, bradiacardia, palpitação, vasoespasmo, cianose, isquemia periférica, arritmia, edema pulmonar, dor abdominal, obstipação, oclusão intestianal, função hepática alterada, colecistite, dermatite e alopecia, e outros);

Se concordar em participar dpo estudo, você receberá a medicação na dose de $5 \mathrm{mg} / \mathrm{kg}$ de peso de acordo com a orientação do pesquisador e será avaliado periodicamaente objetivando detectar os resultados do uso da medicação ou a presença de efeitos colaterais, além de contribuir com o melhor entedimento desta medicação para o tratamento da doença de Crohn.

\footnotetext{
IV - ESCLARECIMENTOS DADOS PELO PESQUISADOR SOBRE GARANTIAS DO SUJEITO DA PESQUISA CONSIGNANDO:

A VOCÊ TAMBÉM ESTÁ RESERVADA A GARANTIA DE DISPOR QUANDO QUISER DE TODA A DOCUMENTAÇÃO MÉDICO-CIENTIIFICA RELATIVA A SEU TRATAMENTO, INCLUSIVE PARA ESCLARECER EVENTUAIS DÚVIDAS. VOCÊ PODE SE RECUSAR A CONTINUAR DENTRO DO ESTUDO QUANDO BEM ENTENDER SEM QUE ISSO TRAGA QUALQUER PREJUÍZO DE SEU TRATAMENTO NESSA INSTITUIÇÃO. A MANUTENÇÃO DO SIGILO E PRIVACIDADE SOBRE AS INFORMAÇÕES RELATIVAS A SEU TRATAMENTO TAMBÉM É NOSSA RESPONSABILIDADE.
} 


\section{INFORMAÇÕES DE NOMES, ENDEREÇOS E TELEFONES DOS RESPONSÁVEIS PELO ACOMPANHAMENTO DA PESQUISA, PARA CONTATO EM CASO DE INTERCORRÊNCIAS CLÍNICAS E REAÇÕES ADVERSAS. \\ Contatos: Dra. Anna Paula Rocha Malheiros (celular: 8431-7980)}

\section{VII - CONSENTIMENTO PÓS-ESCLARECIDO}

Declaro que, após convenientemente esclarecido pelo pesquisador e ter entendido o que me foi explicado, consinto em participar do presente Protocolo de pesquisa.

São Paulo, de de 2006. 


\section{Anexo 4 - Distribuição dos doentes com DC segundo o IADC que}

\section{foram tratados com anti-TNF alfa até a quinta dose}

\begin{tabular}{|c|c|c|c|c|c|c|c|c|}
\hline $\mathrm{n}$ & PROTOCOLO & ESTOMIA & CDAIPRÉ & CDAI1 & CDAI2 & CDAI3 & CDAI4 & CDAI5 \\
\hline 1 & 50 & $\operatorname{sim}$ & $x$ & $x$ & & & & \\
\hline 2 & 165 & sim & $x$ & $x$ & $x$ & $x$ & & \\
\hline 3 & 225 & $\operatorname{sim}$ & $x$ & $x$ & & & & \\
\hline 4 & 261 & $\operatorname{sim}$ & $x$ & $x$ & $x$ & $x$ & $x$ & $x$ \\
\hline 5 & 407 & $\operatorname{sim}$ & $x$ & $x$ & $x$ & & & \\
\hline 6 & 409 & não & 376 & 256 & & & & \\
\hline 7 & 431 & não & & & & & & \\
\hline 8 & 449 & não & 347 & 200 & 235,4 & 214,2 & 166,9 & 149,9 \\
\hline 9 & 477 & não & 184 & 165 & 211,6 & 188,2 & 253,8 & \\
\hline 10 & 480 & $\operatorname{sim}$ & $x$ & $\mathrm{x}$ & $x$ & $x$ & $\mathrm{x}$ & \\
\hline 11 & 524 & $\operatorname{sim}$ & $x$ & $x$ & $x$ & $x$ & $x$ & $x$ \\
\hline 12 & 536 & $\operatorname{sim}$ & $\mathrm{x}$ & $x$ & $x$ & & & \\
\hline 13 & 573 & $\operatorname{sim}$ & $x$ & $x$ & $x$ & $x$ & $x$ & $x$ \\
\hline 14 & 610 & $\operatorname{sim}$ & $x$ & $\mathrm{x}$ & $x$ & & & \\
\hline 15 & 637 & não & & & & & & \\
\hline 16 & 667 & não & 260,6 & 258 & 228 & & & \\
\hline 17 & 675 & $\operatorname{sim}$ & $x$ & $x$ & $x$ & $x$ & & \\
\hline 18 & 692 & não & & & & & & \\
\hline 19 & 693 & não & 178,4 & 133,2 & 128 & & & \\
\hline 20 & 712 & não & & & & & & \\
\hline 21 & 732 & não & 292,6 & 263 & & & & \\
\hline 22 & 735 & não & 184,8 & 98 & 98,4 & & & \\
\hline 23 & 820 & não & 117 & 58 & 62 & 50 & 50 & \\
\hline 24 & 828 & não & 207 & 112 & 112 & 159 & 153 & 101 \\
\hline 25 & 897 & não & 264,5 & 65,8 & 158,8 & 175,6 & & \\
\hline 26 & 900 & não & 133,4 & 111 & 111 & 101,8 & 101,8 & \\
\hline 27 & 901 & não & 112,8 & 62 & 62 & 62 & & \\
\hline 28 & 902 & não & 150 & 28 & 28 & 55,2 & & \\
\hline 29 & 932 & não & 267 & 261 & & & & \\
\hline 30 & 957 & não & & & & & & \\
\hline 31 & 958 & não & 357 & 257,8 & 257,8 & 277,8 & & \\
\hline 32 & 964 & não & 59,8 & 40,2 & 40,2 & 40,2 & 40,2 & \\
\hline 33 & 967 & não & & & & & & \\
\hline 34 & 983 & não & 117,6 & 48 & & & & \\
\hline 35 & 986 & não & 185,6 & 176 & 176 & & & \\
\hline 36 & 991 & não & 152 & 134 & 38 & 68 & 214 & 182 \\
\hline 37 & 994 & não & 161 & 161 & & & & \\
\hline 38 & 1000 & não & 102 & 75 & 69,4 & 64,4 & 59 & 59 \\
\hline 39 & 1041 & $\operatorname{sim}$ & $x$ & $x$ & $x$ & $x$ & $x$ & $x$ \\
\hline 40 & 1053 & não & & & & & & \\
\hline 41 & 1073 & não & 212,2 & 221,6 & 221,6 & & & \\
\hline 42 & 1083 & não & 87 & 79,6 & 79,6 & & & \\
\hline 43 & 1091 & sim & $x$ & $x$ & $x$ & $x$ & $x$ & \\
\hline
\end{tabular}

Continua... 
Conclusão do Anexo 4

\begin{tabular}{|c|c|c|c|c|c|c|c|c|}
\hline $\mathbf{n}$ & PROTOCOLO & ESTOMIA & CDAIPRÉ & CDAI1 & CDAI2 & CDAI3 & CDAI4 & CDAI5 \\
\hline 44 & 1113 & $\operatorname{sim}$ & $\mathrm{x}$ & $\mathrm{x}$ & $\mathrm{x}$ & $\mathrm{x}$ & $\mathrm{x}$ & \\
\hline 45 & 1121 & $\mathrm{não}$ & & & & & & \\
\hline 46 & 1129 & $\mathrm{sim}$ & $\mathrm{x}$ & $\mathrm{x}$ & $\mathrm{x}$ & $\mathrm{x}$ & $\mathrm{x}$ & $\mathrm{x}$ \\
\hline 47 & 1131 & $\mathrm{não}$ & 167,8 & 106,2 & 106,2 & 106,2 & & \\
\hline 48 & 1152 & não & 82 & 30,2 & 30,2 & 30,2 & 30,2 & 30,2 \\
\hline 49 & 1164 & não & & & & & & \\
\hline 50 & 1173 & não & & & & & & \\
\hline 51 & 1207 & não & 314,8 & 201 & & & & \\
\hline 52 & 1214 & não & 148,4 & 128,6 & 220,2 & & & \\
\hline 53 & 1215 & sim & $\mathrm{x}$ & $\mathrm{x}$ & $\mathrm{x}$ & $\mathrm{x}$ & & \\
\hline 54 & 1260 & não & 66,8 & 54,2 & 54,2 & 54,2 & 45,8 & 24,6 \\
\hline 55 & 1276 & não & 154 & 114 & 64,2 & 116 & 129,8 & \\
\hline 56 & 1277 & não & 120 & 62 & 62 & 39,5 & 82,5 & 72,2 \\
\hline 57 & 1328 & não & & & & & & \\
\hline 58 & 1343 & não & 93 & & & & & \\
\hline 59 & 1349 & não & 238,4 & 157,2 & & & & \\
\hline 60 & 1353 & não & 367,2 & 175 & 44,6 & 47,6 & & \\
\hline
\end{tabular}


8. REFERÊNCIAS 
1) Andrade ACM, Santana GO, Santos RR, Guedes JC, Lyra LGC. Perfil da doença de Crohn fistulizante em atividade em dois serviços universitários em Salvador, Bahia. Rev bras colo-proctol. 2005; 25(3):241-248.

2) Aprilli RR, Silva RCP, Feres O. Amputação abdômino-perineal do reto na Doença de Crohn. Rev bras colo-proctol. 2005; 25(4):374-377.

3) Araújo GTB, Fonseca MCM. Custos dos cuidados em doentes com doença de Crohn no Brasil: perspectiva da saúde pública. Value Health. 2007;10(3):A149.

4) Ayrizono MLS, Leal RF, Coy CSR, Fagundes JJ, Góes JRN. Plastias de estenoses de intestino delgado na doença de Crohn: resultados imediatos e tardios. Arq gastroenterol. 2007; 44(3):215-220.

5) Baert, Rutgeerts PR. Anti-TNF strategies in Crohn`s disease: mechanisms, clinical effects, indications. Int J Colorectal Dis. 1999;14:47-51.

6) Balsamo F, Fraga JPB, Moreno WD, Formiga GJS. Doença de Crohn metastática para axila. Rev bras colo-proctol. 2007; 27(1):89-92.

7) Best WR, Becktel JM, Singleton JW,Kern F Jr. Development of a Crohn's Disease Activity Index.Gastroenterology. 1976;70:439-44.

8) Black RA, Rauch CT, Kozlosky CJ, et al. Metalloproteinase disintegrin that releases tumor necrosis factor alpha from cells. Nature 1997; 385:729-733.

9) Cabral VLR, Carvalho L, Miszputen SJ. Importância da albumina sérica na avaliação nutricional e de atividade inflamatória em doentes com doença de Crohn. Arq. Gastroenterol. 2001; 38(2):104-108. 
10) Campos FG, Waitzberg DL, Teixeira MG, Mucerino DR, Habr-Gama A, Kiss DR. Inflammatory bowel diseases: principles of nutritional therapy. Rev Hosp Clin Fac Med Univ Sao Paulo. 2002; 57(4):187-198.

11) Chen $\mathrm{IH}$, Yang KL, Lee A, Huang HH, Lin PY, Lee TD. Low frequency of HLA-b 2706 in Taiwanrse patients with ankylosing spondylitis. Eur $J$ Immunogenet 2002; 29:435-8.

12) Chou CT, Chen JM, Hsu CM, Chen SJ. HLA-B27 and its subtypes in 4 Taiwanese Aborigine tribes: a comparison to Han Chinese patients with ankylosing spondylitis. J Rheumatol. 2003;30:321-5.

13) Coelho JC, Cerveira MO, Machado MB. Manifestações extra-intestinais da doença intestinal inflamatória. Acta Med. 2004; 25:591-601.

14) Crohn BB, Garlock JH, Yarnis H. Right - sided (regional) colitis. JAM.A. 1947;134:334-38.

15) Cruz GMG, Santana JL, Santana SKAA, Constantino JRM, Chamone BC, Ferreira RMRS, Neves PM, Faria MNZ. Exame histopatológico em espécimes de doença hemorroidária operada: revisão de 2.134 casos. Rev bras colo-proctol. 2007; 27(3):269-277.

16) D`Haens GR, et al. Better outcome with potent top-down induction terapy in recent onset Crohn`s disease. Gut. 2005;54 (VII):A17.

17) Damião A, Rodrigues $M$, Damião EBC, Leite AZA, Sipahi AM. Doença inflamatória intestinal retocolite ulcerativa inespecífica e doença de Crohn. Rev Bras Méd. 2006;63:108-122.

18) Damião AOMC, Habr-Gama A. Retocolite Ulcerativa Idiopática (RCUI). In: Dani R, Castro LP. $3^{\mathrm{a}}$.Ed Gastroenterologia Clínica. Rio de Janeiro, GuanabaraKoogan. 1993(1):1037-76. 
19) Damião AOMC, Sipahi AM. Derivados salicílicos no tratamento clínico da doença inflamatória intestinal: novas perspectivas. Rev Hosp Clin Fac Med S Paulo. 1986;41:274-277.

20) Damião AOMC, Sipahi AM. Doença Inflamatória Intestinal. In: Castro LP, Coelho LGV Ed. Gastroenterologia. Rio de Janeiros, Editora MEDSI, 2004:1105-49.

21) Dewulf NLS, Monteiro RA, Passos AFC, Vieira EM, Troncon LEA. Adesão ao tratamento medicamentoso de doentes com doenças inflamatórias intestinais acompanhados no ambulatório de um hospital universitário. Arq gastroenterol. 2007; 44(4):289-296.

22) Elia PP, Fogaça HS, Barros RGGR, Zaltman C, Elia CSC. Análise descritiva dos perfis social, clínico, laboratorial e antropométrico de doentes com doenças inflamatórias intestinais, internados no Hospital Universitário Clementino Fraga Filho, Rio de Janeiro. Arq gastroenterol; 44(4):332-339.

23) Faria FC, Ferrari MLA, Cunha ASC. - Aspectos clínicos da doença de Crohn em um centro de referência para doenças intestinais. GED gastroenterol endosc dig. 2004; 23(4):151-164.

24) Faubion WJ, Loftus EJ, Harmsen WS et AL. The Natural History of Corticosteroid Therapy for Inflammatory Bowel Disease: A population-Based Study. Gastroenterogy. 2001;121:255-260.

25) Fiocchi C. Inflammatory bowel disease: etiology and pathogenesis. Gastroenterology 1998; 115:182-205.

26) Foitzik T, Kruschenwiki M, Kroesen A, Buhr HJ. Does the microcirculation play a role in the pathogenesis of inflammatory bowel disease. Answers from intravital microscopic studies in animal models. Int J Colorectal Dis.1999; 14:29-34. 
27) Gomes CMM, Giraldo PC, Gomes FAM, Amaral R, Passos MLA, Gonçalves AKS. Genital ulcers in women: clinical, microbiologic and histopathologic characteristics. Braz j infect dis. 2007; 11(2):254-260.

28) Gonçalves CG, Carolina Gomes; Coelho JCU, Júlio Cezar Uili; Amarante HMBS. Obstrução intestinal após uso de infliximab no tratamento de fístula êntero-cutânea na doença de Crohn. Rev Col Bras Cir. 2005; 32(4):223-224.

29) Habr-Gama A, Teixeira MG. Doença de Crohn. In: Vinhaes JC. Clínica e terapêutica cirúrgicas. Rio de Janeiro, Guanabara-Koogan. 1997:708-23.

30) Han PD, Cohen RD. Managing immunogenic resposnses to infliximab: treatment implications for patients with Crohn`s disease. Drugs. 2004;64(16):1767-77.

31) Hanauer SB, Feagan BG, Lichtenstein GR, Mayer LF, Schenreiber S, Colombel JF et al. Maintenance infliximab for Crohn`s disease: the ACCENT I randomised trial. Lancet. 2002; 359: 1541-1549.

32) Hanauer SB. Efficacy and safety of tumor necrosis factor antagonists in Crohn`s disease: overview of randomized clinical studies. Rev Gastroenterol Disord. 2004; 4(3): S18-S24.

33) Harvey F, Bradshaw JM. A simple index of Cohn's disease activity. Lancet 1980;1:514-515.

34) Hauer S. Crohn`s disease: step up or top down therapy. Best Pract Res Clin Gastroenterol. 2003;17(1):131-7.

35) Herrlinger KR, Borutta A, Meinhardt G, Stange EF, Fellermann K. Fatal Staplylococcal sepsis in Crohn`s disease after infliximab. Inflamm Bowel Dis. 2004; 10(5): 655-656. 
36) Holtmann MH, Schutz M, Galle PR, Neurath MF. Functional relevance of soluble TNF-alpha, transmembrane TNF-alpha and TNF-signal transduction in gastrointestinal diseases with special reference to inflammatory bowel diseases. Zeitsch Gastroenterol. 2002; 40(8):587-600.

37) Lichtenstein GR, Abreu MT, Cohen R, Tremaine W. American Gastroenterological Association Institute Medical Position Statement on corticosteroids, immunomodulators, and infliximab in inflammatory bowel disease. Gastroenterology 2006:130:935-939.

38) Lichtenstein GR, Yan S, Bala M, Hanauer S. Remission in patients with Crohn's disease is associeted with improvement in employment and quality of life and decrease in hospitalizations and surgeries. Am J Gastroenterol. 2004;99:91-96.

39) Lora FL, Fabiana Lígia; Amarante HMB, Heda M. B; Pisani JC, Júlio C; Borba VVC, Victória V. C; Kulak CAM, Carolina A. M; Carmes ER, Eliane R. Avaliação da densidade mineral óssea em doentes com doença inflamatória intestinal. Arq gastroenterol. 2005; 42(4):201-205.

40) Marchal L, D`Haens G, Van Assche G, Vermeire S, Noman M, Ferrante M et al. The risk of post-operative complications associated with infliximab therapy for Crohn`s disease: a controlled cohort study. Aliment Pharmacol Ther. 2004; 19(7):749-754.

41) Modigliani R. Optimal use of old drugs. In: Caprilli R, ed Inflammatory Bowel Disease-Trigger Factors and Trends in Therapy. Stuttgart, Germany:Schattauer, 1997:129-141.

42) Moss ML, Jin SL, Milla ME, et al. Cloning of a desintegrin metalloproteinase that the processes precursor tumor necrosis factor alpha. Nature. 1997; 385:733-736. 
43) Mota ES, Kiss DR, Teixeira MG, Almeida MG, Sanfront, Azevedo F, Habr-Gama A, Cecconello I. Manifestações extra-intestinais em doença de Crohn e retocolite ulcerativa: prevalência e correlação com o diagnóstico, extensão, atividade, tempo de evolução da doença. Rev bras colo-proctol. 2007; 27(4):349-363.

44) Munkholm $P$, Langholz E, Davidsen $M$, et al. Intestinal cancer risk and mortality in patients with Crohn`s disease. Gastroenterology.1993;105(6):1716-23.

45) Naguchi M, Hiwatashi N, Liu Z, Toyota T. Secretion imbalance between tumor necrosis factor and its inhibitor in inflammatory bowel disease. Gut. 1998;43:203-209.

46) Phelan C. Infliximab and serious hematologic events. CMAJ. 2004;171(9):1045.

47) Portaria no. 858, de 4 de novembro de 2002. Diário Oficial da União - Seção 1 ISSN 1676-2339. No.214, terça-feira, 5 de novembro de 2002. p.77-82.

48) Regueiro MD, Mardin H. Treatment of perianal fistulizing Crohn`s disease with infliximab alone or as na adjunt to exam under anesthesia with seton placement. Inflamm Bowel Dis. 2003;9(2):98-103.

49) Regueiro MD. Update in medical treatment of Crohn`s disease. $J$ Clin Gastroenterol. 2000;31(4):282-91.

50) Reichheld JH, Peppercorn MA. Agents commonly used in the treatment of inflammatory bowel disease. In: Friedman G, Jacobson ED, Mc Callum RW eds. Gastrointestinal Pharmatology \& Therapeutics. Philadelphia, Lippincott-Raven Publishers. 1997:327-347.

51) Rosa SB, Voltarelli JC, Chies JAB, Pranke P. The use of stem cells for the treatment of autoimmune diseases. Rev bras pesqui $m$ d biol. 2007; 40(12):1579-1597. 
52) Rutgeerts P, Van Assche G, Vermeire S. Review article: infliximab therapy for inflammatory bowel disease -seven years on. Aliment Pharmacol Ther. 2006; 23:451-463.

53) Salomão EC, Salomão BC, Salomão FC, Daud MS, Salomão PR, Borges VFA. Doença de Crohn confinada ao apêndice vermiforme, apresentando-se como apendicite aguda: relato de caso. ABCD arq bras cir dig. 2004; 17(4):182-183.

54) Salviano FN, Burgos MGPA, Santos EC. Perfil socioeconômico e nutricional de doentes com doença inflamatória intestinal internados em um hospital universitário. Arq Gastroenterol. 2007; 44(2):99-106.

55) Salviano FN, Santos EMC, Burgos MGPA. Terapia nutricional na doença inflamatória intestinal: enfoque na fase ativa da doença. An Fac Med Univ Fed Pernamb. 2006; 51(1):37-44.

56) Sandborn WJ. New concepts in anti-tumor necrosis factor therapy for inflammatory bowel disease. Rev Gastroenterol Disord. 2005;5(1): 10-18.

57) Sands BE, Anderson FH, Bernstein CN, Chey WY, Feagan BG et al. .Infliximab maintenance therapy for fistulizing Crohn`s disease. $N$ Engl $J$ Med. 2004;350:876-85.

58) Sands BE. Why do anti-tumor necrosis factor antibodies work in Crohn`s disease?. Rev Gastroenterol Disord. 2004;4(3): S10-S17.

59) Schottelius AJ, Baldwin AS Jr. A role of transcription factor NF-kappa B in intestinal inflammation. Int J Colorectal Dis. 1999;14:18-28.

60) Seddik M, Meliez H, Seguy D, Viget N, Cortot A, et al. Pneumocystis Jiroveci (Carinii) Pneumonia Following initiation of infliximab and azathioprine therapy in a patient with Crohn`s disease. Inflamm Bowel Dis. 2004;10(4):436-437. 
61) Singh SM, Rau NV, Cohen LB, Harris H. Cutaneous nocardiosis complicating management of Crohn`s disease with infliximab and prednisone. CMAJ.2004;171(9).doi:10.1503/cmaj.1040563.

62) Tapajós M, Coelho HS, Elia C, Zalteman S, Lewis-Ximenes L, Pitrowsky M, Moraes E, Fogaça H. Prevalence of hepatitis $C$ virus and evaluation of associated risk factors in a group of Braziliam patients with inflammatory bowel disease. GED gastroenterol endosc dig. 2005; 24(3):121-134.

63) Targan SR, Hanauer SB, van Deventer SJ et al. A short-term study of chimeric monoclonal antibody cA2 to tumor necrosis factor alpha for Crohn`s disease. Crohn`s Disease cA2 Study Group. N Engl J Med. 1997; 337:1029-35.

64) Targan SR. Biology of inflammation in Cronh's disease: mechanisms of action of anti-TNF-a therapy. Can J Gastroenterology. 2000;14:13-16.

65) Teixeira M, Fergunson A. Uses and limitations of the Crohn`s disease activity index. Arq Gastroenterol. 1979;16(2):67-72.

66) Teixeira MG, Habr-Gama A, Takiguti C, Calache JE, Almeida MG, Teixeira WG, Pinotti HW. Colonic Crohn's diseases: results of treatment. Rev Hosp Clin Fac Med S Paulo. 1998; 53(2):61-7.

67) Teixeira MG, Sousa M, Almeida MG, Silva Filho E, Ponte A, Calache JE, HabrGama A, Kiss DR. Resultados da proctocolectomia total com ileostomia definitiva (PCT) na doença de Crohn (DC). Rev. bras. colo-proctol. 2002; 22(4):233-238.

68) Teixeira MG. Doença de Crohn - operações eletivas: quando operar e como proceder. In: Atualização em cirurgia do aparelho digestivo e coloproctologia. São Paulo: Frontis Editorial; 2004. p. 285-287. 
69) Valério F, Cutait R, Sipahi A, Damião A, Leite K. Câncer em doença de Crohn: relato de caso. Rev. bras. colo-proctol. 2006; 26(4):443-446.

70) Van Assche G, Magdelaine-Beuzelin C, D'Haens G, Baert F, Noman M, Vermeire S, Ternant D, Watier H, Paintaud G, Rutgeerts P. Withdrawal of Immunosuppression in Crohn's Disease Treated With Scheduled Infliximab Maintenance: A Randomized Trial. Gastroenterology, In Press, Uncorrected Proof, Available online 8 March 2008. doi:10.1053/j.gastro.2008.03.004

71) Van Deventer SJH. Tumor necrosis factor and Crohn's disease. Gut 1997; 40:443-448.

72) Van Dullemenn HM, Van Deventer SJ, Hommes DW, Bijl HÁ, Jansen J et al. Treatment of Crohn`s disease with anti-tumor necrosis factor chimeric monoclonal antibody (cA2). Gastroenterology. 1995;109(1):129-35.

73) Viana MLL, Pontes RMA, Garcia WE, Fávero ME, Prete DC, Matsuo T. Doença de Crohn e cálculo renal: muito mais que coincidência? Arq. Gastroenterol. 2007; 44(3):210-214.

74) Wright JP, Marks IN, Parfitt A. Simple clinical index of Crohn's disease activity - the Cape Town index. South African Medical Journal 1986; 68:502-503.

75) Yoshida EM. The Crohn`s Disease Activity Index, its derivatives and the Inflammatory Bowel Disease Questionnaire: a review of instruments to assess Crohn`s disease. Can J Gastroenterol. 1999;13(1):65-73. 